
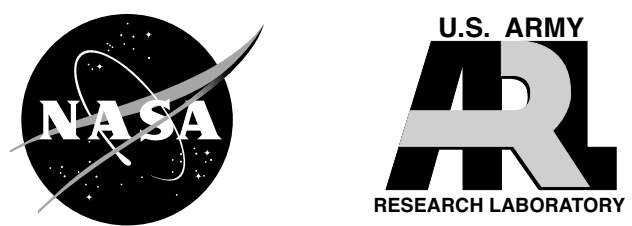

DBD Plasma Actuators for Flow Control in Air Vehicles and Jet Engines - Simulation of Flight Conditions in Test Chambers by Density Matching

David E. Ashpis

Glenn Research Center, Cleveland, Ohio

Douglas R. Thurman

U.S. Army Research Laboratory, Glenn Research Center, Cleveland, Ohio 


\section{NASA STI Program . . . in Profile}

Since its founding, NASA has been dedicated to the advancement of aeronautics and space science. The NASA Scientific and Technical Information (STI) program plays a key part in helping NASA maintain this important role.

The NASA STI Program operates under the auspices of the Agency Chief Information Officer. It collects, organizes, provides for archiving, and disseminates NASA's STI. The NASA STI program provides access to the NASA Aeronautics and Space Database and its public interface, the NASA Technical Reports Server, thus providing one of the largest collections of aeronautical and space science STI in the world. Results are published in both non-NASA channels and by NASA in the NASA STI Report Series, which includes the following report types:

- TECHNICAL PUBLICATION. Reports of completed research or a major significant phase of research that present the results of NASA programs and include extensive data or theoretical analysis. Includes compilations of significant scientific and technical data and information deemed to be of continuing reference value. NASA counterpart of peer-reviewed formal professional papers but has less stringent limitations on manuscript length and extent of graphic presentations.

- TECHNICAL MEMORANDUM. Scientific and technical findings that are preliminary or of specialized interest, e.g., quick release reports, working papers, and bibliographies that contain minimal annotation. Does not contain extensive analysis.

- CONTRACTOR REPORT. Scientific and technical findings by NASA-sponsored contractors and grantees.
- CONFERENCE PUBLICATION. Collected papers from scientific and technical conferences, symposia, seminars, or other meetings sponsored or cosponsored by NASA.

- SPECIAL PUBLICATION. Scientific, technical, or historical information from NASA programs, projects, and missions, often concerned with subjects having substantial public interest.

- TECHNICAL TRANSLATION. Englishlanguage translations of foreign scientific and technical material pertinent to NASA's mission.

Specialized services also include creating custom thesauri, building customized databases, organizing and publishing research results.

For more information about the NASA STI program, see the following:

- Access the NASA STI program home page at http://www.sti.nasa.gov

- E-mail your question via the Internet to help@ sti.nasa.gov

- Fax your question to the NASA STI Help Desk at 443-757-5803

- Telephone the NASA STI Help Desk at 443-757-5802

- Write to: NASA Center for AeroSpace Information (CASI) 7115 Standard Drive Hanover, MD 21076-1320 

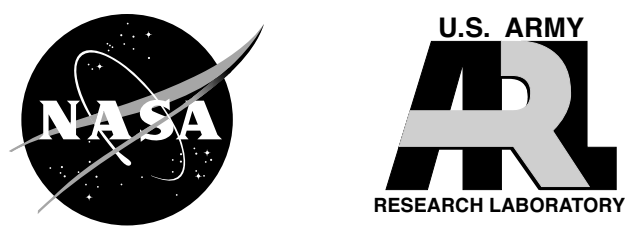

\section{DBD Plasma Actuators for Flow Control in Air Vehicles and Jet Engines-Simulation of Flight Conditions in Test Chambers by Density Matching}

David E. Ashpis

Glenn Research Center, Cleveland, Ohio

Douglas R. Thurman

U.S. Army Research Laboratory, Glenn Research Center, Cleveland, Ohio

Prepared for the

42nd Plasmadynamics and Lasers Conference

sponsored by the American Institute of Aeronautics and Astronautics

Honolulu, Hawaii, June 27-30, 2011

National Aeronautics and

Space Administration

Glenn Research Center

Cleveland, Ohio 44135 


\section{Acknowledgments}

This project was supported by the NASA Subsonic Fixed Wing Project of the Fundamental Aeronautics Program. We wish to thank Scott Jones, Michael Tong, and Chris Snyder from NASA Glenn Research Center for their help in developing the engine models. Thanks also to Alex Likhanskii (Tech-X Corporation), Andrey Starikovskiy (Princeton University), and Mikhail Shneider (Princeton University) for useful discussions. Thanks for NASA Glenn Publishing department-Nancy Mieczkowski for the graphics, Lisa Greeney for layout, and Mary Eitel-Kim for coordinating production of this report.

\section{Document Change History}

NASA/TM-2011-217006/REV1, July 2011

DBD Plasma Actuators for Flow Control in Air Vehicles and Jet Engines-Simulation of Flight Conditions in

Test Chambers by Density Matching

David E. Ashpis and Douglas R. Thurman

This printing replaces NASA/TM—2011-217006, March 2011, because extensive changes were made to the document.

This report contains preliminary findings, subject to revision as analysis proceeds.

This work was sponsored by the Fundamental Aeronautics Program at the NASA Glenn Research Center.

Level of Review: This material has been technically reviewed by technical management.

Available from

NASA Center for Aerospace Information 7115 Standard Drive

Hanover, MD 21076-1320
National Technical Information Service 5301 Shawnee Road Alexandria, VA 22312 


\title{
DBD Plasma Actuators for Flow Control in Air Vehicles and Jet Engines-Simulation of Flight Conditions in Test Chambers by Density Matching
}

\author{
David E. Ashpis \\ National Aeronautics and Space Administration \\ Glenn Research Center \\ Cleveland, Ohio 44135 \\ Douglas R. Thurman \\ U.S. Army Research Laboratory \\ Glenn Research Center \\ Cleveland, Ohio 44135
}

\begin{abstract}
We address requirements for laboratory testing of Dielectric Barrier Discharge (DBD) plasma actuators for active flow control in air vehicles and jet engines. The performance of these actuators depends on the gas discharge properties, which in turn, depend on the pressure and temperature. When performing a characterization of actuators in a laboratory chamber without external flow, the test-chamber pressure and temperature must be set to the flight pressure and temperature at the actuator location. It is desirable to perform the tests at room temperature because it is technically challenging to simultaneously set pressure and high temperature in a chamber. We make the assumption that the plasma discharge depends only on the gas density, and ignore all other temperature effects. The tests can then be performed at room temperature with chamber pressure set to match the density in flight conditions. We calculated the needed test-chamber pressures for altitude flight of an air vehicle, and for jet engines at sea-level takeoff and altitude cruise conditions. For air vehicles, we show several examples of the chamber pressure dependence on flight at altitudes up to $65,000 \mathrm{ft}$. For jet engines, we first generated the needed data by constructing generic models of four engine thrust classes; 300-, 150-, and 50-passenger (PAX) aircraft engines, and a military jetfighter engine. We calculated the static and total pressure, temperature, and density distributions along the engine for sea-level takeoff and for altitude cruise conditions, and we present the corresponding test-chamber pressures. The range is from 12.4 to $0.03 \mathrm{~atm}$, depending on the altitude, the engine class, and the placement of the actuator. For example, if a DBD plasma actuator is placed at the compressor exit of a 300 PAX engine, it must be tested at $12.4 \mathrm{~atm}$ for takeoff, and at $6 \mathrm{~atm}$ for cruise. If it is placed at the low-pressure turbine exit, the test pressures are 0.5 and $0.2 \mathrm{~atm}$, respectively. The engine models are non-proprietary and the data can be used for evaluation requirements of other types of actuators and for other purposes. We also included the distributions of unit Reynolds number, Mach number and velocity along the engines.
\end{abstract}

\section{Nomenclature}

$\begin{array}{ll}H, h & \text { Altitude } \\ \mathrm{M} & \text { Mach number } \\ P & \text { Static pressure } \\ R & \text { Gas constant } \\ R e y & \text { Reynolds number } \\ T & \text { Static temperature } \\ V & \text { Velocity } \\ X & \text { Axial distance along the engine } \\ \rho & \text { Density }\end{array}$

Subscripts:

c Conditions in chamber

$\infty \quad$ Freestream conditions

atm Atmospheric conditions 
Acronyms:

$\begin{array}{ll}\text { DBD } & \text { Dielectric Barrier Discharge } \\ \text { HPC } & \text { High Pressure Compressor } \\ \text { HPT } & \text { High Pressure Turbine } \\ \text { LPC } & \text { Low Pressure Compressor } \\ \text { LPT } & \text { Low Pressure Turbine } \\ \text { PAX } & \text { Passengers }\end{array}$

\section{Introduction}

There is a strong interest in active flow control techniques for applications in air vehicles as well as in jet engines; for example, to eliminate flow separation, improve efficiency or reduce noise (Ref. 1). Dielectric Barrier Discharge (DBD) plasma actuators have been proposed for active flow control of various flows, and the technology has been an active research area in the last decade.

The main active flow control technique in aerodynamics is based on injection of small jets in a steady or unsteady manner into the flow. The small input creates a large global effect that provides the desired flow improvement. DBD plasma actuators create a wall-jet by purely electronic means. The jet can be operated in steady mode, or in unsteady mode (by pulsing or modulating), and it can be used for active flow control, similar to any pneumatically- or mechanically-generated jet.

A DBD actuator is shown in Figure 1. The actuator consists of a pair of thin conducting electrodes separated by a dielectric. Usually there is one exposed electrode and one covered electrode and the electrodes are offset. Typically, at atmospheric conditions, a high voltage ( 1 to $40 \mathrm{kV}$ RMS), high frequency (1 to $20 \mathrm{kHz}$ ) signal is applied to the electrodes, creating localized weakly ionized gas plasma discharge on the surface near the edge of the exposed electrode. A typical discharge is shown in Figure 2.

The jet is generated in the plasma region via the electrohydrodynamic effect, a process of collisions between ions and neutral molecules in the plasma. The actuator construction is very simple, but the physical mechanisms involved are quite complex and include interactions among electrical fields, electrons, positively and negatively charged species, the electrodes, and the dielectric surface (Refs. 2 to 4). Gas is drawn from the surroundings to form a thin wall jet that is roughly parallel to the surface and directed away from the exposed electrode edge in the direction of the covered electrode, as visualized by experiments and computation (Refs. 5 to 7). There is slight heating involved, but its effect on the jet is negligible. Other types of plasma-based flow control devices that generate localized intense heating (Ref. 8) are not included in the scope of devices addressed in this paper. More detailed information and references on DBD actuators and their application for aerodynamic flow control can be found in several review articles (Refs. 9 to 12).

The advantages of DBD actuators are that they are surface-mounted, fully electronic, low power, high frequency-band devices. There are no moving parts, tubes, ducts or surface holes. Flexible operation is possible by controlling the input voltage and waveforms. DBD plasma actuators are particularly attractive for gas turbine and turbomachinery applications; they are thin, surface mounted, and do not require internal volumes or passages. Their construction can be made suitable for a high-temperature environment by choosing high-temperature alloys for the electrodes and temperature-resistant ceramic materials for the dielectric. They can easily be integrated with futuristic engine components to be made of ceramics and composites.

The majority of the research in the DBD actuators area has been focused on applications in external flows, particularly for wings and airframes, rather than on propulsion. But there have been important efforts directed at turbomachinery applications. There have been several successful experimental demonstrations of active flow control with DBD plasma actuators to eliminate low Reynolds number separation in Low-Pressure Turbine flows (Refs. 13 to 16), and to reduce effects of turbine tip leakage (Refs. 17 to 20). Those experiments were performed in wind tunnels or linear cascades at room temperature.

DBD actuators need to be tested in actual flight conditions in order to be used as flow control devices in practical applications. Only a few flight tests were performed on air vehicles; on a small remotely controlled airship (Refs. 21 and 22), a full-size piloted glider (Ref. 23), and a small UAV (Ref. 24), but no tests have been performed in jet engines. Before performing flight tests, the actuators must be tested in the laboratory. The aerodynamic performance of the actuators must be characterized to prove that they have sufficient authority at the flow conditions at the location of their placement in the air vehicle or jet engine. In addition, the electrical performance, particularly the power consumption of the actuators, must be quantified, as it is needed for design of power supplies and for costbenefit analysis of the flow control technology. This paper addresses the test conditions needed to characterize the actuators in the laboratory. 
The basic characterization in the laboratory is performed without external flow. The aerodynamic performance is characterized by measuring the velocity profile of the wall jet and/or the thrust generated by the actuator. The electrical performance is characterized by measuring the current, voltage, and power. Most of the tests to date have been performed at room temperature and atmospheric conditions, but in order to simulate flight conditions the actuator must be placed in a chamber with controlled temperature and pressure representative of the flow conditions in flight. A small number of tests are reported in the literature in chambers at room temperature and sub-atmospheric conditions, with some conflicting results (Refs. 25 through 32). Tests at atmospheric altitude conditions have been performed in an environmental chamber (Ref. 33), where temperature and pressure were varied simultaneously. These tests were primarily motivated by their applicability to external aerodynamics. Tests at above-atmospheric pressures at room temperature were reported in References 34 and 35, and were mainly motivated by their application to internal aerodynamics.

The actuator performance must be tested in conditions that simulate the operating conditions in flight, at the location where the actuator is placed. The applications in the jet engine are particularly challenging because of the high temperatures and high pressure ratios in several engine components. It is challenging to simultaneously set pressure and high temperature in a test chamber, and therefore it is desirable to find a simpler approach to eliminate this technical complication. The question that arises is how to simulate the conditions in an operating jet engine in order to test the actuators properly. Because the principle of operation of DBD actuators depends on electrical discharges and on the associated force generation mechanisms, the performance of the actuator will be affected by the pressure, temperature and properties of the gas. It is assumed that for the range of temperatures in atmospheric flight and in the jet engine, the gas density alone is the significant gas property influencing the performance of the actuator. Therefore, the flight conditions can be simulated by matching the density in the laboratory. It is a simple idea that has not been proposed before.

The outline of this paper is as follows. After addressing a relatively simple case of an air vehicle flying at altitude, attention is focused on the jet engine applications. First, information is provided on pressure, temperature, density, unit Reynolds number, Mach number, and velocity distribution along the flow-path of four thrust classes of jet engines. This information is derived from non-proprietary engine models used in system analysis studies done by NASA. These models include cycle, flow path and sizing. Then, by setting the test-chamber pressure at room temperature, the density in the chamber is matched to the in-flight operating conditions. The range of the needed chamber pressures was calculated by matching the densities and using the ideal gas law. It depends on the placement of the actuator, and the results are presented for the four engine classes at takeoff and cruise conditions. This information is useful as a guideline for testing requirements of DBD plasma actuators at engine flight conditions. The engine information documented here, which is often hard to find in publicly available sources, is useful for evaluation of other types of actuators as well as for other purposes.

\section{Jet Engine Data Source—Engine Models}

The engine models used in this study were developed based on information available in the open literature and from empirical estimates. Cycle analysis was performed with the Numerical Propulsion Simulation System (NPSS) code (Refs. 36 and 37), providing performance parameters such as thrust, component pressure ratios, and velocities, temperatures, and pressures at each engine station. Aeromechanical analysis and estimates of engine and component weights were calculated using the Weight Analysis of Turbine Engines (WATE) code (Ref. 38), which also provides a flow path schematic of the engine. Generic engine models representing four different thrust classes were developed: 300-, 150- and 50-passenger (PAX) aircraft engines, and a military jet-fighter engine. These models are a good representation of actual engines. Note that the 150 PAX model is a conceptual design of a generic geared high bypass turbofan. The primary engine parameters of thrust, weight, overall pressure ratio, and bypass ratio are listed in Table 1 and the schematic of each engine is shown in Figure 3. The axial coordinates of the components' outflow stations are listed in Table 2.

Engine conditions were calculated at the inlet and exit flow stations of the various engine components. Data were acquired for two engine operating conditions: sea-level takeoff and altitude cruise at 35,000 ft. Data for the 50 PAX engine are also shown for an additional cruise altitude of $65,000 \mathrm{ft}$, as this type of engine is also used for high-flying air vehicles. Figures 4 through 7 show the following parameters for each engine: static and total (stagnation) pressure, temperature, and density, as well as unit Reynolds number, Mach number and velocity. Ideal gas conditions were assumed. For all data shown, the flights Mach numbers are $\mathrm{M}=0.8$ at cruise, and $\mathrm{M}=0$ at takeoff. Figure 6(d2) for the 50 PAX engine also shows unit Reynolds number for cruise Mach numbers of $\mathrm{M}=0.5$, 0.6 , and 0.8 at altitude of $65,000 \mathrm{ft}$. 
There are more data presented than are strictly needed for development of the subject test conditions. The reason for including the extra data is to make them available to the research community because it is hard to find nonproprietary actual engine data. The engine data presented here are unrestricted and can be used for other purposes.

\section{Test Conditions for DBD Plasma Actuators}

\section{A. Assumptions}

Several assumptions are used to develop the test conditions in laboratory experiments in quiescent environment (no flow) in a test-chamber:

1) The effects of temperature and pressure on plasma kinetics and chemistry are ignored. This assumption is reasonable for the range of temperatures in the jet engines, and is further discussed below.

2) The effect of temperature on the electrical properties of the actuator, particularly on the capacitance of the dielectric, is negligible. The capacitance variation was calculated in Reference 33, and was shown to be small.

3) Actuator heat generation is negligible. This assumption is based on experimental observations for the range of power and voltages applied to conventional DBD plasma actuators.

4) Gas thermodynamic properties are constant (except in the engine model data calculations).

5) Gas composition effects are ignored. There is a small effect of the composition of the atmosphere variation with altitude mainly due to variation of the oxygen/nitrogen ratio (Ref. 32). Effects due to the presence of combustion products in the areas of the engine downstream of the combustors, and effects of humidity are assumed to be insignificant.

6) Gas viscosity is assumed not to affect the actuator performance. In principle, viscosity dependence on temperature can affect the development of the wall-jet generated by the actuator. (Sutherland's law was used in calculating the unit Reynolds number in the engine models.)

The main assumption is that the gas density is the only parameter that governs the physical process of the walljet generation by the plasma discharge. A process of collisions between ions and neutral molecules creates the forces that result in the wall-jet. The collisions are governed by the mean-free-path and the number of molecules in a unit volume. Therefore, with the assumptions listed above, the gas density in laboratory tests should be set to be equal to the density at the application flight conditions.

Assessment of the validity of these assumptions and possible subsequent refinements are a subject for future work. With these assumptions, the main factor affecting the jet generation dependence on pressure and temperature is captured by considering only the density.

Validation of the assumption that temperature affects only the density is not trivial. It is known that some of the reactions between different charged molecules and electrons in the plasma are temperature dependent. Usually the dependence is weak, except for the temperature dependence of electron attachment processes, which can be significant above $1800^{\circ} \mathrm{R}(1000 \mathrm{~K})$. It seems that the only practical approach to assess the full effect of temperature and pressure on the momentum transferred to the fluid is to use numerical simulation of the DBD plasma actuator at different temperatures and pressures. This simulation is challenging and is planned to be performed in the future. The authors are not aware of any reported work on this topic.

The assumption that the temperature affects only the density is very reasonable for temperatures under $1800{ }^{\circ} \mathrm{R}$ $(1000 \mathrm{~K})$. The open question is whether it is significant at higher temperature levels. If it turns out to have a large effect, it is expected to affect the calculated test conditions only for jet engine applications in the combustion chamber and the high-pressure turbine, which are at temperatures higher than $1800{ }^{\circ} \mathrm{R}$, as seen from Figures 4 through 7.

\section{B. Test-chamber pressure}

The chamber pressure and temperature to yield the same density as in flight are calculated as follows:

The gas density in the laboratory test chamber should be the same as the density at the application flight conditions,

$$
\rho_{c}=\rho
$$

where subscript $c$ indicates conditions in the chamber.

Assuming an ideal gas of a fixed species, and therefore with constant $R$, 


$$
\rho=P / R T
$$

the following relationship is obtained

$$
P_{c}=\frac{P}{\left(T / T_{c}\right)}
$$

where

$P_{c}, T_{c}, \rho_{c}$ - Laboratory chamber pressure, temperature, and density.

$P, T, \rho-$ Static pressure, temperature, and density at flight conditions

\section{Test-chamber pressures for air vehicles}

The chamber pressures $P_{c}$ were calculated first for the case of an air vehicle (Figure 8). An air vehicle is flying at altitude $h$ at Mach number $\mathrm{M}_{\infty}$. The atmospheric pressure at altitude $h$ is $P_{a t m}(h)$ and the temperature is $T_{a t m}(h)$, and are given by Standard Atmosphere tables. The local Mach number at the actuator location is M, which can be larger or smaller than $\mathrm{M}_{\infty}$, depending on the flow development on the body, as determined by its geometry and

flight conditions. We assume isentropic flow without shock waves. Using isentropic relationships at the freestream and at the actuator placement location with common stagnation conditions, and taking the atmospheric conditions at altitude $h$ as the static conditions, we obtain:

$$
P_{c}=T_{c} \frac{P_{a t m}(h)}{T_{a t m}(h)} \frac{f(\mathrm{M})}{f\left(\mathrm{M}_{\infty}\right)}
$$

where

$$
f(\mathrm{M})=\left(1+\frac{\gamma-1}{2} \mathrm{M}^{2}\right)^{\frac{-1}{\gamma-1}}
$$

The chamber pressures for the following special cases are:

1) Actuator placed on a stationary vehicle at altitude $h$ : $\mathrm{M}_{\infty}=0, \mathrm{M}=0$

Therefore $f\left(\mathrm{M}_{\infty}\right)=1, f(\mathrm{M})=1$, and we obtain from Eq. (4),

$$
P_{c}=T_{c} \frac{P_{a t m}(h)}{T_{a t m}(h)}
$$

This result is expected, as the static density on a stationary vehicle is the same at the atmosphere density.

2) Actuator placed on a flat plate at altitude $h$ at zero angle of attack: $\mathrm{M}_{\infty}=\mathrm{M}$

We obtain from Eq. (4) the same relationship,

$$
P_{c}=T_{c} \frac{P_{a t m}(h)}{T_{a t m}(h)}
$$

This result is also expected, as the static conditions are the same as the atmospheric conditions.

3) Actuator placed at the stagnation point (as is common for flow control of airfoil leading edge stall):

$\mathrm{M}=0$, and we obtain from Eq. (4) 


$$
P_{c}=T_{c} \frac{P_{a t m}(h)}{T_{a t m}(h)} \frac{1}{f\left(\mathrm{M}_{\infty}\right)}
$$

The chamber pressure $P_{c}$ is shown in Figure 8 as a function of altitude for the first two cases (Eq. (6)), and for flight Mach numbers $\mathrm{M}_{\infty}=0.5$, with local Mach numbers of $\mathrm{M}=0$ (stagnation point) and $\mathrm{M}=0.8$ ((Eq. (4)). A curve for $M_{\infty}=1$ with local Mach number of $M=0$ (stagnation point), representing an extreme case, is also shown. An example of a flow with shocks is also presented in Figure 8, for an actuator placed behind the oblique shock wave on a $20^{\circ}$ wedge at $\mathrm{M}_{\infty}=2$. Isentropic conditions were assumed upstream and downstream of the shock, and oblique shock relations were used to calculate the flow conditions on the wedge surface downstream of the shock.

The calculations are relatively straight forward for the shown simplified air vehicle cases. Obtaining the density at the placement location of actuators in actual configuration and flow conditions will involve obtaining data from CFD or measurement, taking into account viscosity and non-isentropic flows.

\section{Test-chamber pressures for jet engines}

The situation for gas turbine engine application is more complex than for air vehicles because of the turbomachinery components and the combustion processes. The test-chamber pressures needed for jet engine applications were calculated from the engine model data for the four generic engine classes. In these calculations, sea-level pressure was $14.7 \mathrm{psi}$, and sea-level temperature was $545.7^{\circ} \mathrm{R}\left(29.8^{\circ} \mathrm{C}\right)$. The latter was also taken as the value of the chamber room temperature. The results are displayed in Figure 9. Some notes on the calculations are provided in the next section.

\section{Discussion}

For the air vehicle application, the chamber pressures decrease with altitude according to the variation of density with altitude and local flow conditions at the actuator location. The situation is more complex for the jet engine. The results show that the test-chamber pressure varies greatly across the different engine classes, from sub-atmospheric to above atmospheric pressures, depending on the operating conditions and location of the actuator in the engine. For example, if a DBD plasma actuator is to be placed at the inlet to the high pressure turbine for the 300 PAX engine, it must be tested at $6 \mathrm{~atm}$ if it is intended to operate at sea-level takeoff conditions, and at $2.9 \mathrm{~atm}$ if it is intended to operate at $35,000 \mathrm{ft}$ cruise. If it is to be used in the exit of the high-pressure compressor duct (burner inlet), it must be tested at $12.4 \mathrm{~atm}$ at takeoff conditions, and at $6.2 \mathrm{~atm}$ at $35,000 \mathrm{ft}$ cruise conditions. If it is to be used at the low-pressure turbine exit, it must be tested at $0.5 \mathrm{~atm}$ for operation at takeoff, and at $0.2 \mathrm{~atm}$ at cruise. If the actuator is to be placed on the low-pressure turbine of the 50 PAX engine flying at 65,000 ft, its performance must be tested at a very low chamber pressure of $0.03 \mathrm{~atm}$.

Note that the calculations are based on conditions at the inflow and outflow planes of the various engine components. The calculated points are connected with straight lines. Further modification is needed to account for local flow conditions inside the component. For example, in turbomachinery there are inter-row and inter-stage variations, and in inter-blade passages there is acceleration or diffusion or even shock waves that will modify the results. Those local modifications are not included in this study and are left for future work.

Note also that the results shown in Figure 9 display the chamber pressures based on total (stagnation) as well as static conditions in the engine. The reason that the results corresponding to total conditions are shown is that the total conditions are equal to static conditions at locations where the velocity is zero, corresponding to placement of the actuator at locations such as the leading edge of a turbine or compressor airfoil. As can be seen in the figure, the differences are not large.

Additional insights can be gained from the distribution of the unit Reynolds number. Usually, a low unit Reynolds number may indicate flow separation. For example, it is known that there is a tendency for flow separation on the low-pressure turbine (LPT) suction surface at altitude. Low Reynolds number locations are good candidates for implementation of active flow control. However, those locations are also characterized by low density, requiring the plasma actuator to be tested at low chamber pressures. DBD plasma actuators may suffer from loss of performance as the density is decreased (note that there are insufficient and conflicting results in the published literature on this matter). Therefore, laboratory testing is critical for establishing that the DBD actuators can perform adequately under low density conditions. 
It is important to note that for research in the field of weakly ionized plasma, laboratory experiments were traditionally performed in a vacuum chamber at room temperature. It therefore became common in that field to specify the chamber pressure as an experimental parameter. This may have led to habitually considering the pressure, rather than the density, as the relevant parameter.

\section{Conclusions}

Data on flow conditions in four generic jet engines, representing four different thrust classes, were presented, and, because they are non-proprietary, the data are useful for various applications related to formulating test conditions of flow control devices placed in various engine components. The data were used to develop test conditions for characterization of DBD plasma actuators in a chamber at room temperature. The underlying assumption is that the performance of DBD actuators depends only on the density and that all other temperaturerelated effects are negligible over the temperature range existing in the jet engine. Based on this assumption, and the engine models' data, the required test-chamber pressure for simulating in-flight engine operating conditions was calculated. The pressures vary with the location of the actuator in the engine, the type of engine, and the flight operating conditions. There is a wide spread in the pressure range, depending on the specific application. The pressure varies from 12.4 to $0.03 \mathrm{~atm}$ for the four engine classes' models and the flight conditions studied. Chamber pressures needed to test actuators for flight vehicles were also shown. Unlike the engine environment, the flow conditions for testing flight vehicles can simply be calculated with data readily available from standard atmospheric tables, for any flight speed and altitude. Modifications can be added to account for local flow conditions at actuator placement. The test pressures presented rely heavily on the density matching assumption. Deviation from this assumption is not expected to be large, and it is believed that the results are correct to at least first order.

\section{References}

1. Lord, W.K., MacMartin, D.G., and Tillman G., "Flow Control Opportunities in Gas Turbine Engines," AIAA2000-2234, 2000.

2. Likhanskii, A.V., Shneider, M.N., Macheret, M.O., and Miles, R.B., "Modeling of Interaction Between Weakly Ionized Near-Surface Plasmas and Gas Flow," AIAA-2006-1204, 2006.

3. Likhanskii, A.V., Shneider, M.N., Opaits, D.F., Miles, R.B., and Macheret, S.O., "Numerical Modeling of DBD Plasma Actuators and the Induced Air Flow," AIAA-2007-4533, 2007.

4. Likhanskii, A.V., "Study of Plasma Phenomena at High Electric Fields in Applications for Active Flow Control and Ultra-Short Pulse Laser Drilling," Ph.D. Dissertation, The Pennsylvania State University, College Station, PA, 2009.

5. Corke, T.C., Jumper, E.J., Post, M.L., Orlov, D., and McLaughlin, T.E., "Application of Weakly-Ionized Plasmas as Wing Flow-Control Devices," AIAA-2002-350, 2002.

6. Suzen, Y.B., Huang, P.G., Jacob, J.D., and Ashpis, D.E., "Numerical Simulations of Plasma Based Flow Control Applications," AIAA-2005-4633, 2005.

7. Suzen, Y.B., Huang, P.G., and Ashpis, D.E., "Numerical Simulations of Flow Separation Control in LowPressure Turbines Using Plasma Actuators," AIAA-2007-937, 2007.

8. Samimy, M., Adamovich, I., Webb, B., Kastner, J., Hileman, J., Keshav, S., and Palm, P., "Development and Characterization of Plasma Actuators for High Speed and Reynolds Number Jet Control," Experiments in Fluids, Vol. 37 (4), 2004, pp. 577-588.

9. Moreau, E., "Airflow Control by Non-Thermal Plasma actuators," J. Phys. D: Appl. Phys. Vol. 40, 2007, pp. 605-636.

10. Corke, T.C., Post, M.L., and Orlov, D.M., "SDBD Plasma enhanced Aerodynamics: Concepts, Optimization and Applications," Progress in Aerospace Sciences Vol. 43, 2007, pp. 193-217.

11. Corke, T.C., Post, M.L., and Orlov, D.M., "Single Dielectric Barrier Discharge Plasma Enhanced Aerodynamics: Physics, Modeling and Applications," Exp. Fluids, Vol. 46, 2009, pp. 1-26.

12. Corke, T.C., Enloe, C.L., and Wilkinson, S.P., "Dielectric Barrier Discharge Plasma Actuators for Flow Control," Annu. Rev. Fluid Mech. Vol. 42, 2010, pp. 505-29.

13. Hultgren, L.S., and Ashpis, D.E., "Demonstration of Separation Delay with Glow-Discharge Plasma Actuators," AIAA-2003-1025, 2003.

14. List, J., Byerley, A.R., McLaughlin, T.E., and VanDyken, R.D., "Using a Plasma Actuator to Control Laminar Separation on a Linear Cascade Turbine Blade," AIAA-2003-1026, 2003.

15. Huang J., Corke T.C., and Thomas F.O., "Plasma Actuators for Separation Control of Low Pressure Turbine Blades," AIAA J., Vol. 44, 2006, pp. 51-57. 
16. Huang J., Corke T.C., and Thomas F.O., "Unsteady Plasma Actuators for Separation Control of Low-Pressure Turbine Blades," AIAA J., Vol. 44, 2006, pp. 1477-87.

17. Morris, S.C., Corke, T.C., VanNess, D., Stephens, J., and Douvillev, T., "Tip Clearance Control Using Plasma Actuators," AIAA-2005-782, 2005.

18. VanNess, D.K., Corke, T.C., and Morris S.C., "Turbine Tip Clearance Flow Control Using Plasma Actuators," AIAA-2006-21, 2006.

19. Douville, T., Stephens J., Corke T., Morris S., “Turbine Blade Tip Leakage Flow Control by Partial Squealer Tip and Plasma Actuators," AIAA-2006-20, 2006.

20. VanNess, D.K., Corke, T.C., and Morris S.C., "Tip Clearance Flow Visualization of a Turbine Blade Cascade with Active and Passive Flow Control," ASME Paper No. GT2008-5070, 2008.

21. Göksel, B., Fischer, M., Rechenberg, I., and Thallemer, A., "Elektrostatischer Plasma-Wellantrieb für Bionische Luftschiffe," Proceedings of the German Aerospace Congress 2005, Friedrichshafen, Germany, Deutsche Gesellschaft für Luft- und Raumfahrt Paper No. DGLR-2005-261, Vol. 3, 2005, pp. 1853-1856.

22. Göksel, B., Private Communication, 2008, http://www.electrofluidsystems.com/airfish/b-ionic-airfish2008.wmv [cited 15 June 2011].

23. Sidorenko, A., Budovsky, A., Pushkarev, A., and Maslov, A., "Flight Testing of DBD Plasma Separation Control System," AIAA-2008-373, 2008.

24. Grundmann, S., Frey, M., and Tropea, C., "Unmanned Aerial Vehicle (UAV) with Plasma Actuators for Separation Control," AIAA-2009-698, 2009.

25. Abe, T., Takizawa, Y., Sato, S., and Kimura, N., “A Parametric Experimental Study for Momentum Transfer by Plasma Actuator," AIAA-2007-187, 2007.

26. Gregory, J.W., Enloe, C.L., Font, G.I., and McLaughlin, T., "Force Production Mechanisms of a DielectricBarrier Discharge Plasma Actuator," AIAA-2007-185, 2007.

27. Schuele, C.Y. and Corke, T., "Characteristics of Single Dielectric Barrier Discharge Plasma Actuators at Subatmospheric Pressures," 61st Annual Meeting of the APS/DFD, San Antonio, Texas, Nov. 2008, http://meetings.aps.org/link/BAPS.2008.DFD.ET.9 [cited 15 June 2011].

28. Takagaki, M., Isono, S., Nagai, H., and Asai, K., "Evaluation of Plasma Actuator Performance in Martian Atmosphere for Applications to Mars airplanes," AIAA-2008-3762, 2008.

29. Benard, N., Balcon, N., and Moreau, E., "Electric Wind Produced by a Surface Dielectric Barrier Discharge Operating in Air at Different Pressures: Aeronautical Control Insights," J. Phys D: Appl. Phys., Vol. 41, 2008, pp. 042002.

30. Benard, N., Balcon, N., and Moreau, E., "Electric Wind Produced by a Single Dielectric Barrier Discharge Actuator Operating in Atmospheric Flight Conditions: Pressure Outcome," AIAA-2008-3792, 2008.

31. Valerioti, J., and Corke, T., "Effect of Dielectric Properties on Functional Relationship between Plasma Initiation and Ambient Pressure," 62nd Annual Meeting of the APS/DFD, Minneapolis, MN, Nov 2009. http://meetings.aps.org/link/BAPS.2009.DFD.GD.1 [cited 15 June 2011].

32. Font, G.I., Enloe, C.L., Newcomb, J.Y., Teague, A.L., Vasso, A.R., and McLaughlin, T.E., "Effects of Oxygen Content on the Behavior of the Dielectric Barrier Discharge Aerodynamic Plasma Actuator," AIAA-2010-545, 2010.

33. Benard, N., and Moreau, E., "Effects of Altitude on the Electromechanical Characteristics of Dielectric Barrier Discharge Plasma Actuators," AIAA-2010-4633, 2010.

34. Valerioti, J.A., "Pressure Dependence of Plasma Actuated Flow Control," MS Thesis, University of Notre Dame, Indiana, 2010.

35. Valerioti, J., and Corke, T., "Pressure Dependence of Plasma Actuated Flow Control," 63rd Annual Meeting of the APS Division of Fluid Dynamics, Long Beach, California, November 2010. http://meetings.aps.org/link/BAPS.2010.DFD.QJ.4 [cited 15 June 2011]. Also: Submitted for AIAA Journal.

36. Lytle, J.K., "The Numerical Propulsion Simulation: An Overview,” NASA/TM-2000-209915, 2000.

37. Jones, S.M., “An Introduction to Thermodynamic Performance Analysis of Aircraft Gas Turbine Engine Cycles Using the Numerical Propulsion System Simulation Code," NASA/TM-2007-214690, 2007.

38. Tong, M.T., Naylor, B.A., "An Object-Oriented Computer Code for Aircraft Engine Weight Estimation," ASME Paper No. GT2008-50062, 2008. 
TABLE 1.-PARAMETERS OF FOUR ENGINE MODELS

\begin{tabular}{|l|c|c|c|c|c|}
\hline \multicolumn{1}{|c|}{ Engine } & Thrust & Weight & \multicolumn{2}{|c|}{ OPR } & BPR \\
\hline & At sea-level static & Bare engine & Overall Pressure Ratio & Bypass Ratio \\
\hline & $(\mathrm{lbf})$ & $(\mathrm{lb})$ & At sea-level & At 35k ft & At 35k ft \\
\hline 300PAX & 86,700 & 18,400 & 37.8 & 45.7 & 8.3 \\
\hline 150PAX (future) & 23,400 & 5,100 & 33.5 & 42.0 & 14.3 \\
\hline 50PAX & 7,600 & 1,300 & 23.5 & 28.4 & 5.3 \\
\hline Military & 18,500 & 3,800 & 33.4 & 33.6 & 0.4 \\
\hline
\end{tabular}

TABLE 2.-AXIAL COORDINATES OF ENGINE MODEL COMPONENTS

\begin{tabular}{|c|c|c|c|c|c|c|c|}
\hline \multicolumn{2}{|r|}{300 PAX } & \multicolumn{2}{|r|}{150 PAX } & \multicolumn{2}{|c|}{50 PAX } & \multicolumn{2}{|c|}{ Military } \\
\hline $\begin{array}{l}\mathrm{X}, \\
\text { in. }\end{array}$ & $\begin{array}{c}\text { Component } \\
\text { outflow plane }\end{array}$ & $\begin{array}{l}\mathrm{X}, \\
\text { in. }\end{array}$ & $\begin{array}{c}\text { Component } \\
\text { outflow plane }\end{array}$ & $\begin{array}{l}\mathrm{X}, \\
\text { in. }\end{array}$ & $\begin{array}{c}\text { Component } \\
\text { outflow plane }\end{array}$ & $\begin{array}{l}X, \\
\text { in. }\end{array}$ & $\begin{array}{c}\text { Component } \\
\text { outflow plane }\end{array}$ \\
\hline \multicolumn{2}{|r|}{ Core } & \multicolumn{2}{|r|}{ Core } & \multicolumn{2}{|r|}{ Core } & \multicolumn{2}{|r|}{ Core } \\
\hline-60 & Ambient & -45 & Ambient & -20 & Ambient & -20 & Ambient \\
\hline 0 & Inlet & 0 & Inlet & 0 & Inlet & 0 & Inlet \\
\hline 24 & Fan & 15 & Fan & 6 & Fan & 22 & Fan \\
\hline 24 & Splitter & 15 & Splitter & 12 & Duct & 25 & Duct \\
\hline 26 & Duct & 15 & Duct & 46 & HPC & 56 & HPC \\
\hline 46 & LPC & 28 & LPC & 48 & Duct & 60 & Duct \\
\hline 59 & Duct & 39 & Duct & 55 & Burner & 69 & Burner \\
\hline 110 & HPC & 65 & HPC & 58 & HPT & 77 & HPT \\
\hline 111 & Duct & 66 & Duct & 59 & Duct & 78 & TDuct \\
\hline 120 & Burner & 73 & Burner & 71 & LPT & 86 & LPT \\
\hline 129 & HPT & 77 & HPT & 86 & Mixer & 95 & Mixer \\
\hline 138 & Duct & 84 & Duct & 103 & Nozzle & 106 & Duct \\
\hline 181 & LPT & 100 & LPT & \multicolumn{2}{|r|}{ Bypass } & 146 & Augmentor \\
\hline 188 & Duct & 103 & Duct & -20 & Ambient & 190 & \begin{tabular}{|l|} 
Nozzle \\
\end{tabular} \\
\hline 212 & Core Nozzle & 115 & Core Nozzle & 0 & Inlet & \multicolumn{2}{|r|}{ Bypass } \\
\hline \multicolumn{2}{|r|}{ Bypass } & \multicolumn{2}{|r|}{ Bypass } & 6 & Fan & -20 & Ambient \\
\hline-60 & Ambient & -45 & Ambient & 71 & Duct & 0 & Inlet \\
\hline 0 & Inlet & 0 & Inlet & 86 & Duct & 22 & Fan \\
\hline 24 & Fan & 15 & Fan & & & 86 & Duct \\
\hline 24 & Splitter & 15 & Splitter & & & 95 & Mixer \\
\hline 59 & Bypass EGV & 30 & Bypass EGV & & & & \\
\hline 95 & Duct & 47 & Duct & & & & \\
\hline 149 & Bypass Nozzle & 86 & Bypass Nozzle & & & & \\
\hline
\end{tabular}




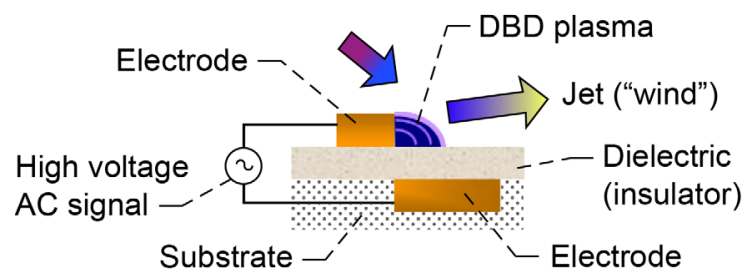

Figure 1.-Schematic of a DBD plasma actuator.

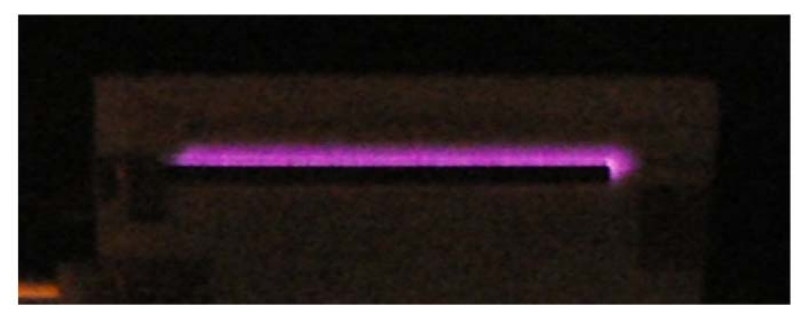

Figure 2.-Top view of typical DBD discharge (Alumina dielectric with copper electrodes, NASA GRC experiment). 

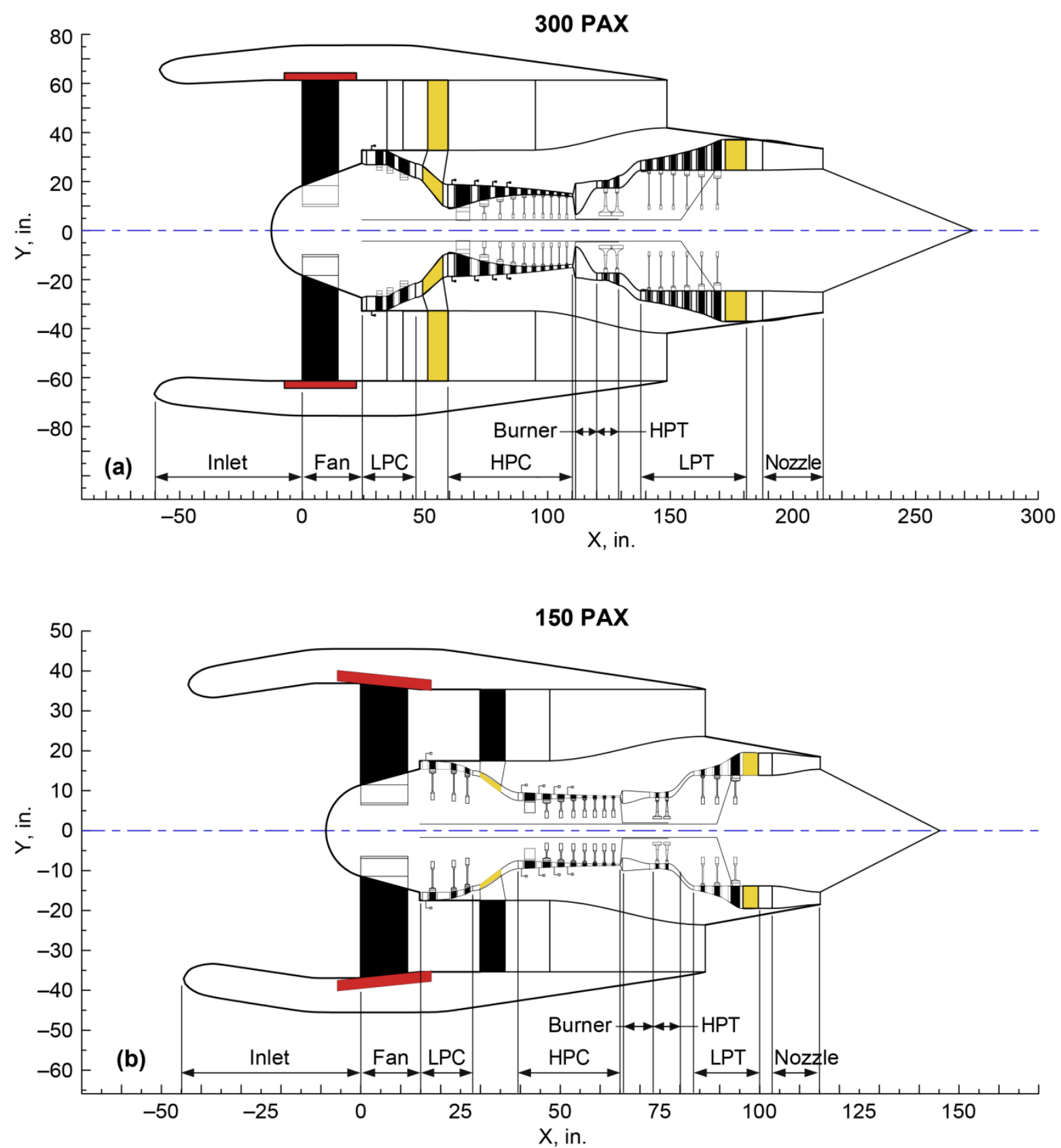

Figure 3.-Schematics of four engine models. (a) 300 PAX. (b) 150 PAX. 

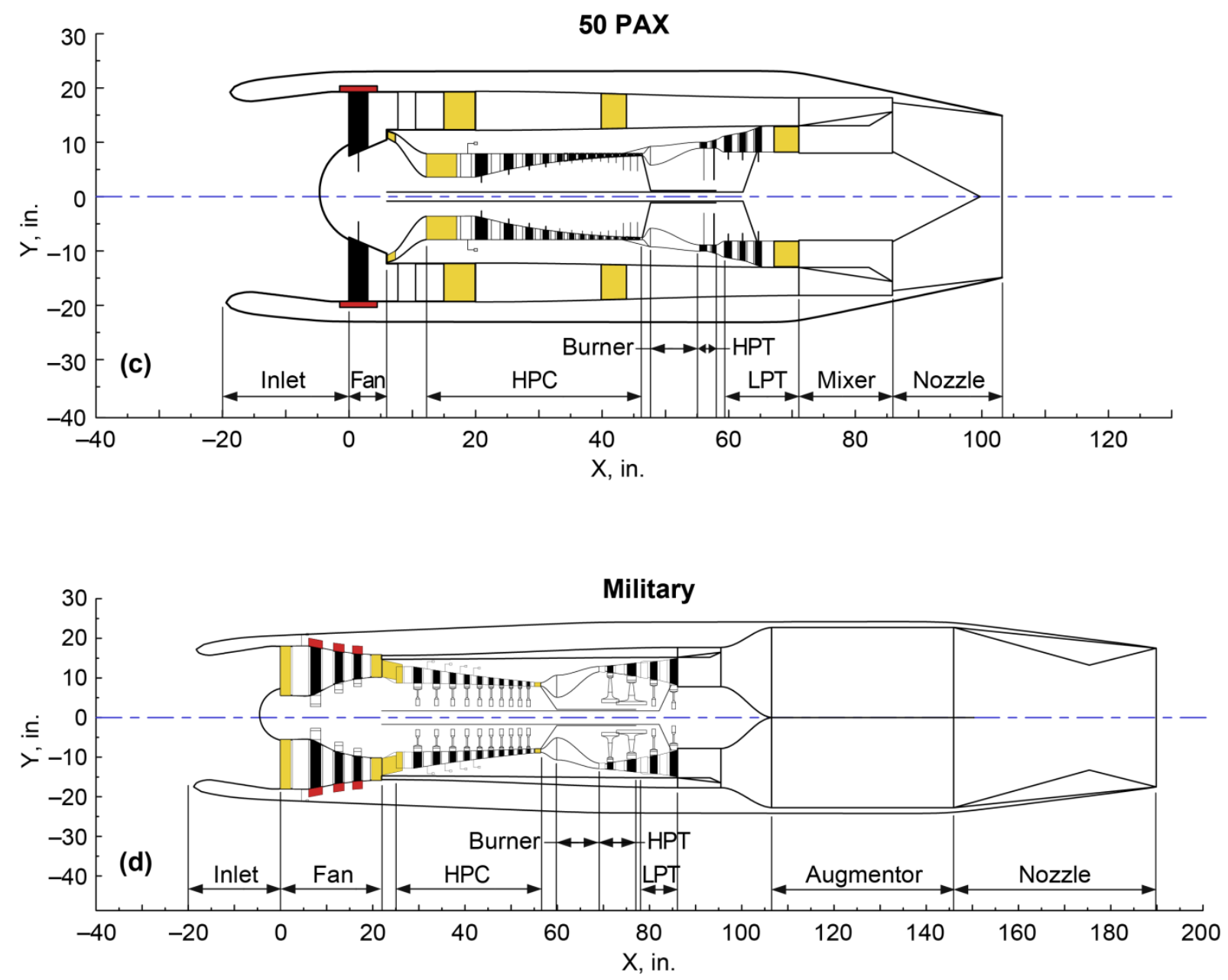

Figure 3.-Schematics (concluded). (c) 50 PAX. (d) Military. 


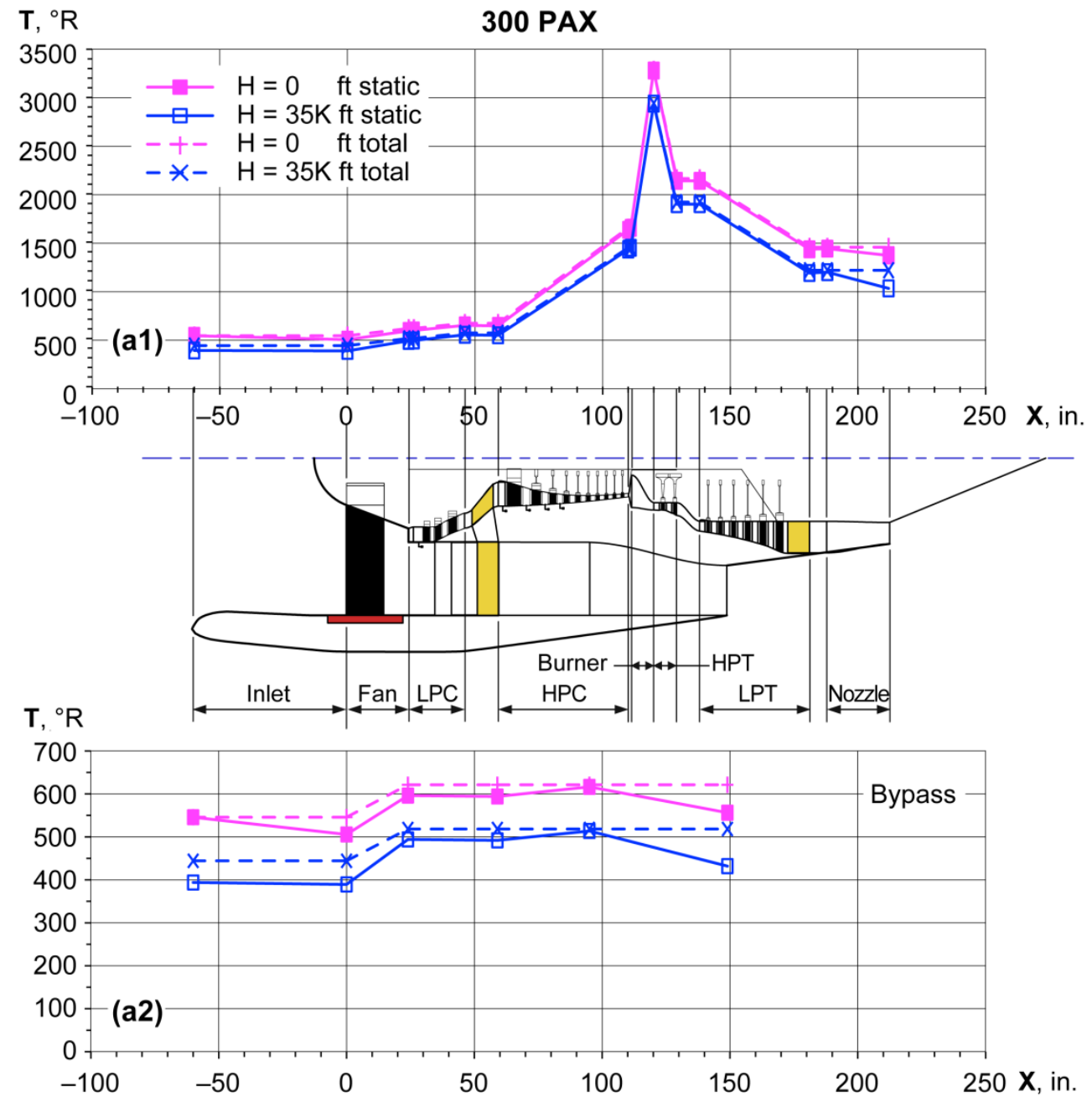

Figure 4a.-300 PAX engine-static and total temperatures. (a1) Core flow-path. (a2) Bypass. 

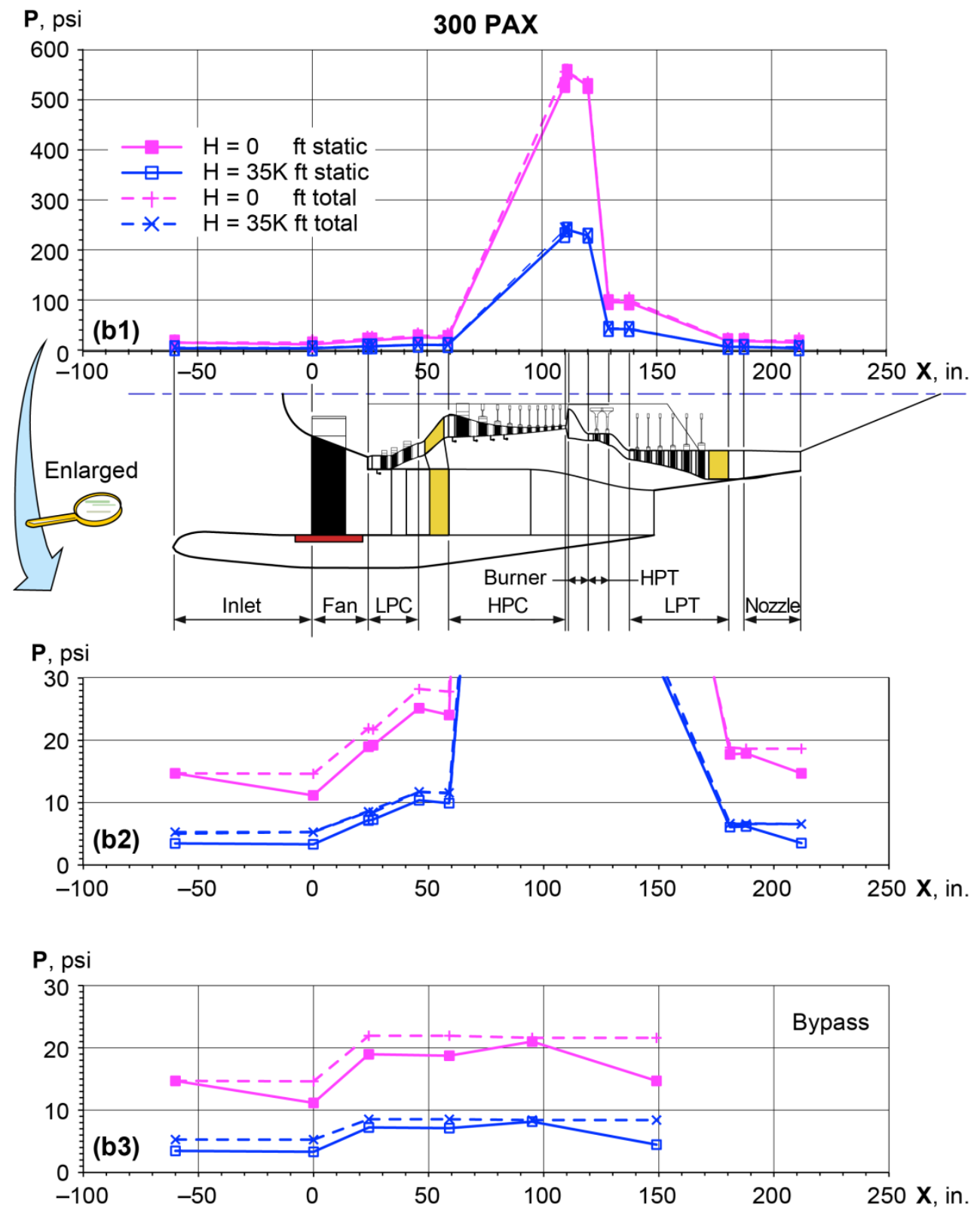

Figure 4b.-300 PAX engine-static and total pressures. (b1) Core flow-path full-pressure scale. (b2) Enlargement of (b1). (b3) Bypass. 


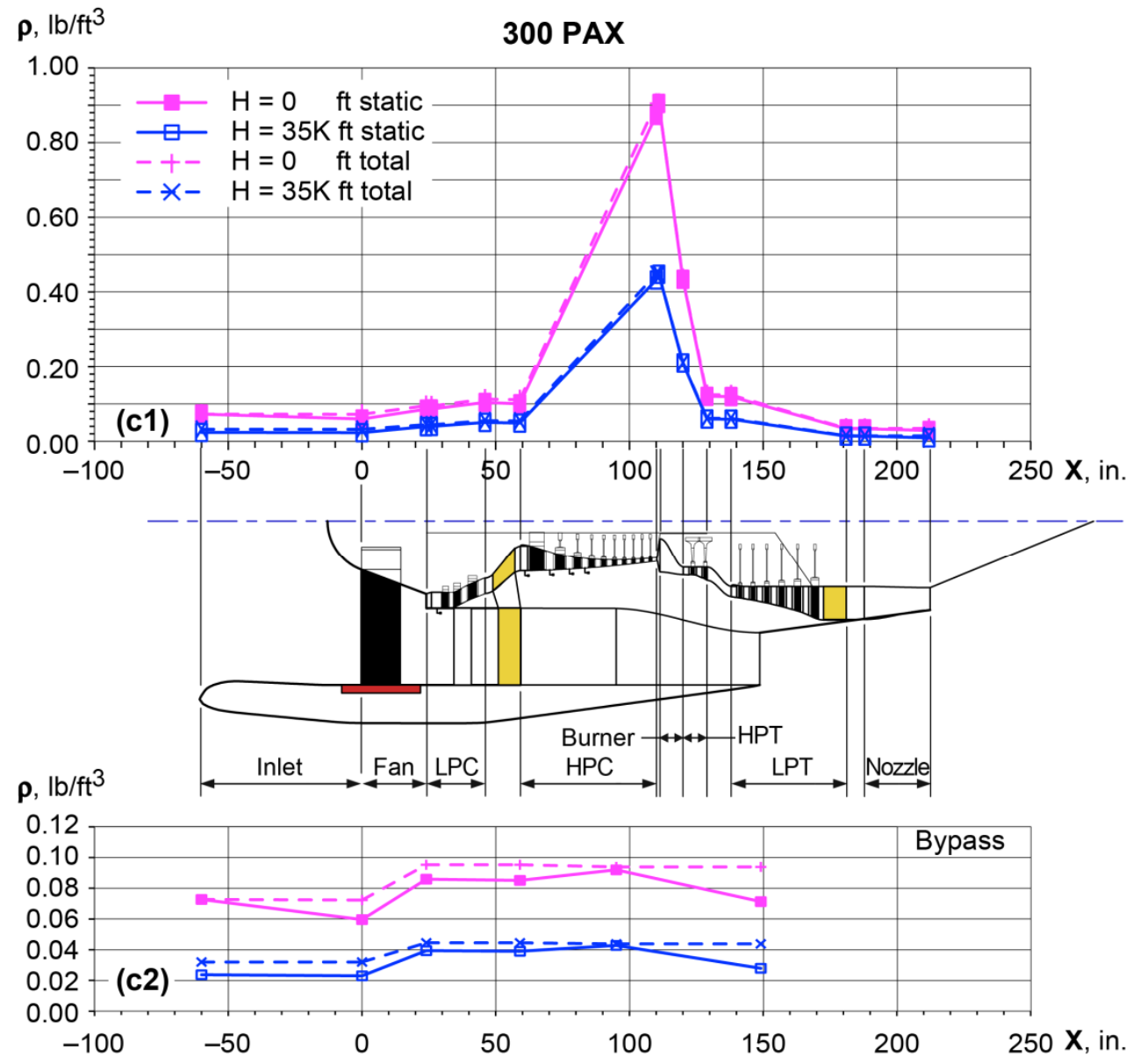

Figure 4c.-300 PAX engine-static and total densities. (c1) Core flow-path. (c2) Bypass. 


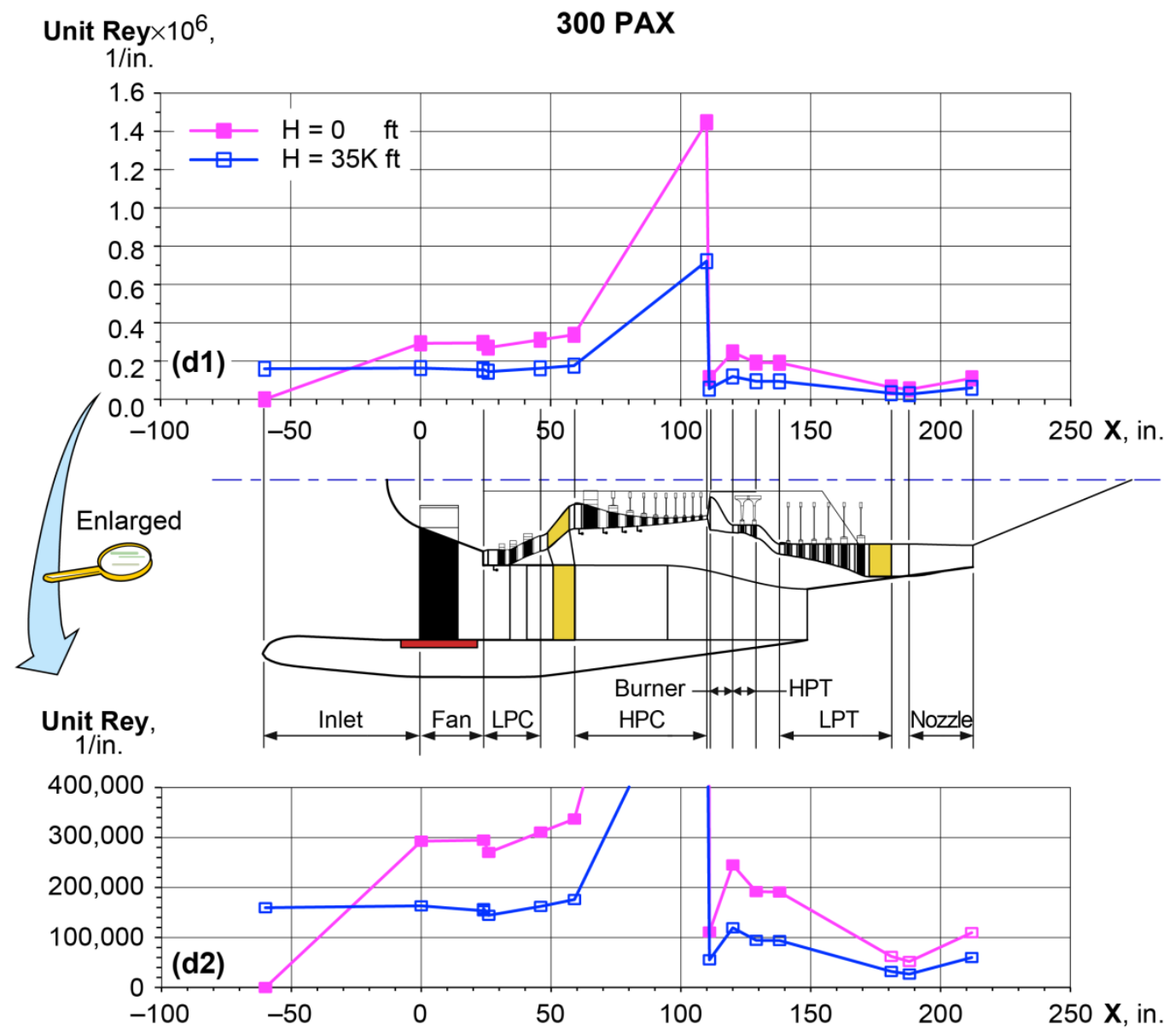

Figure 4d.-300 PAX (d1) unit Reynolds number in core flow-path. Full unit Reynolds number scale. (d2) Enlargement. 


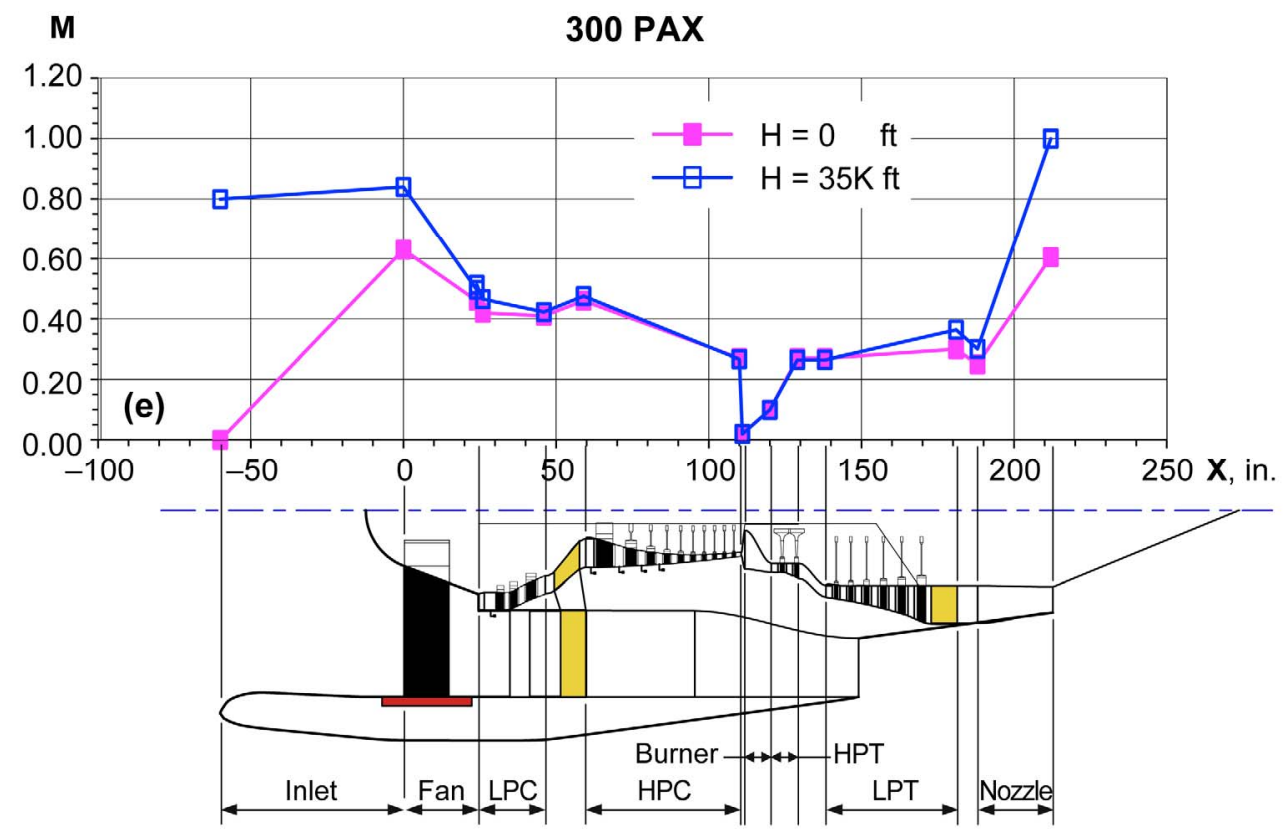

Figure 4e.-300 PAX engine-Mach number in the core flow-path.

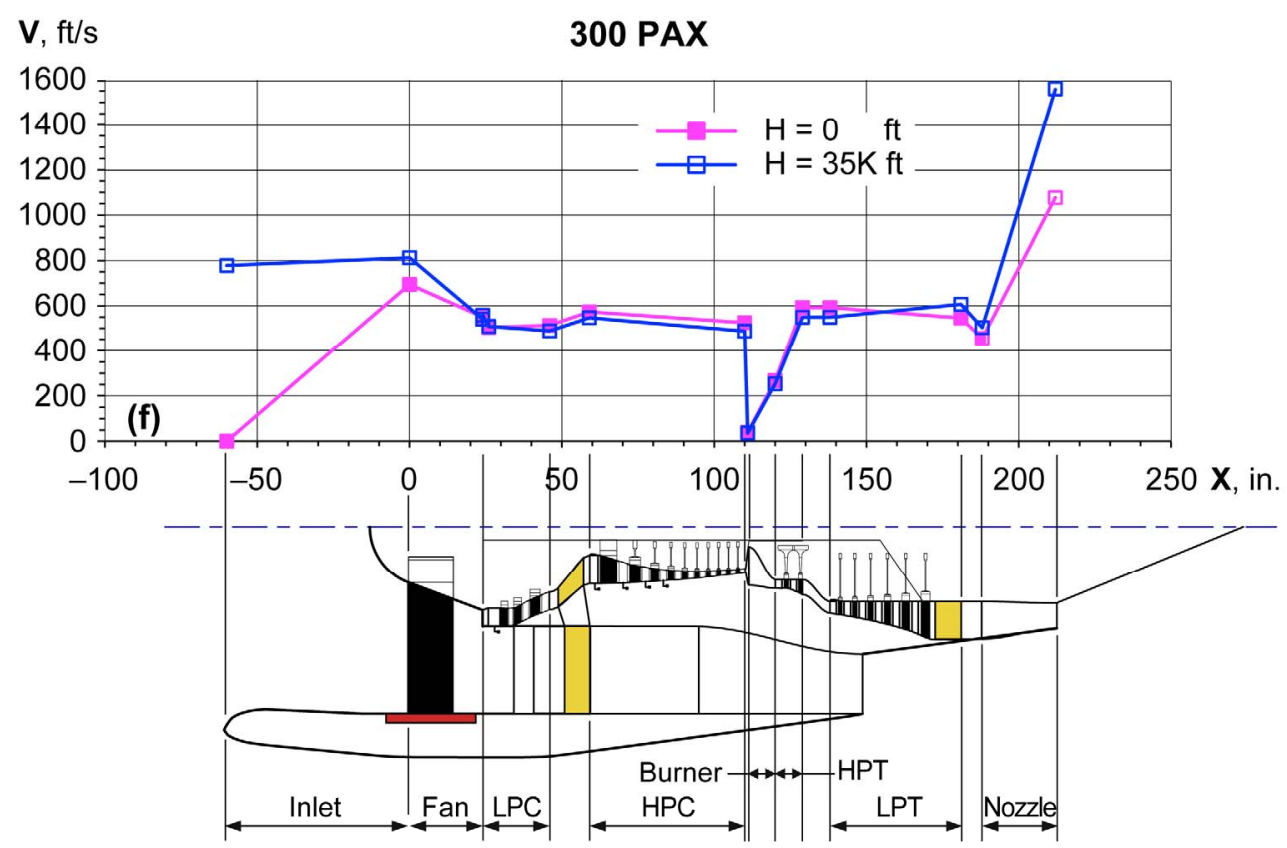

Figure 4f.-300 PAX engine-Velocity in the core flow-path.

Figure 4.-Engine data for 300 PAX engine model (a) Temperatures. (b) Pressures. (c) Densities.

(d) Unit Reynolds number. (e) Mach number, (f) Velocity, for sea-level takeoff and 35,000 ft cruise. 


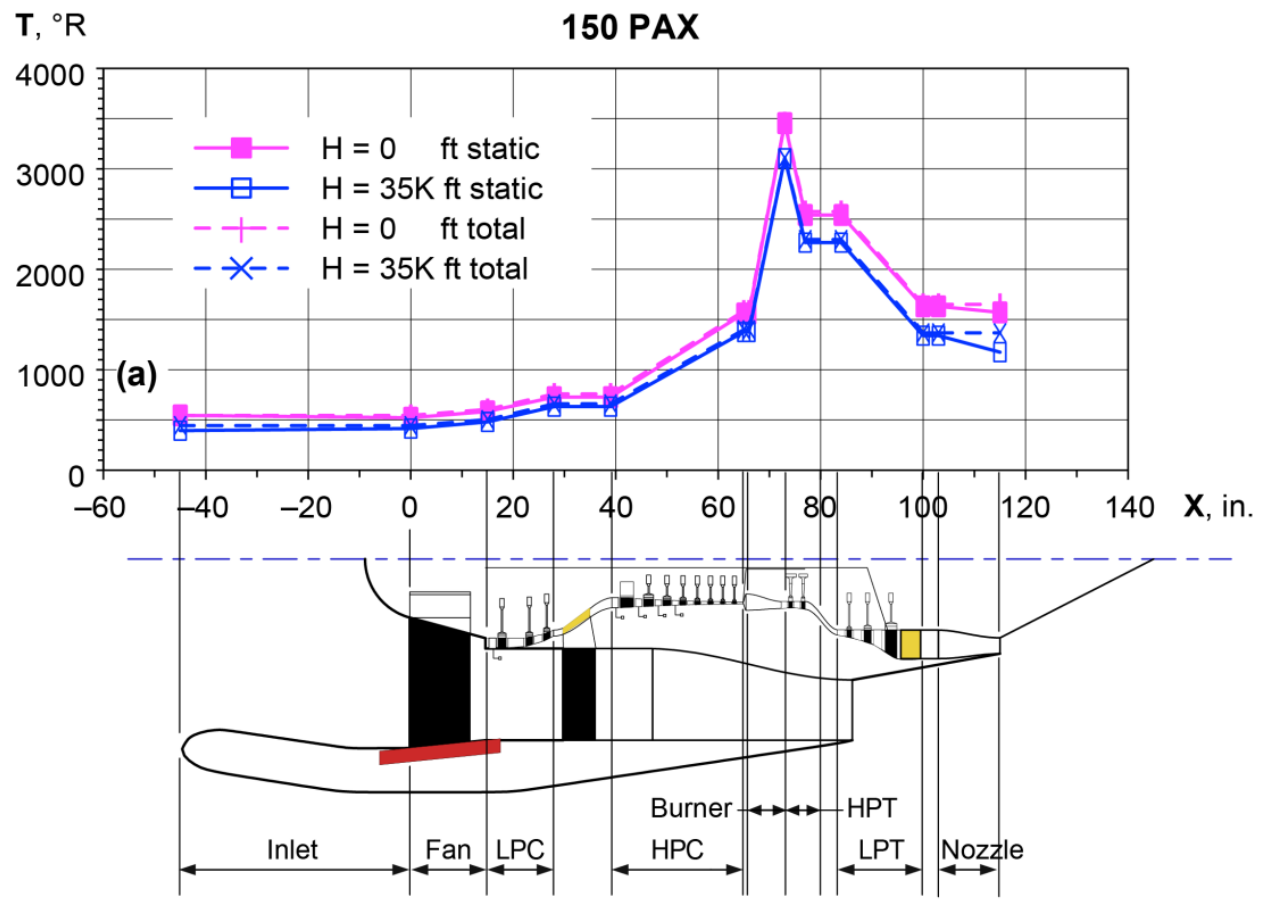

Figure 5a.-150 PAX engine-static and total temperatures.

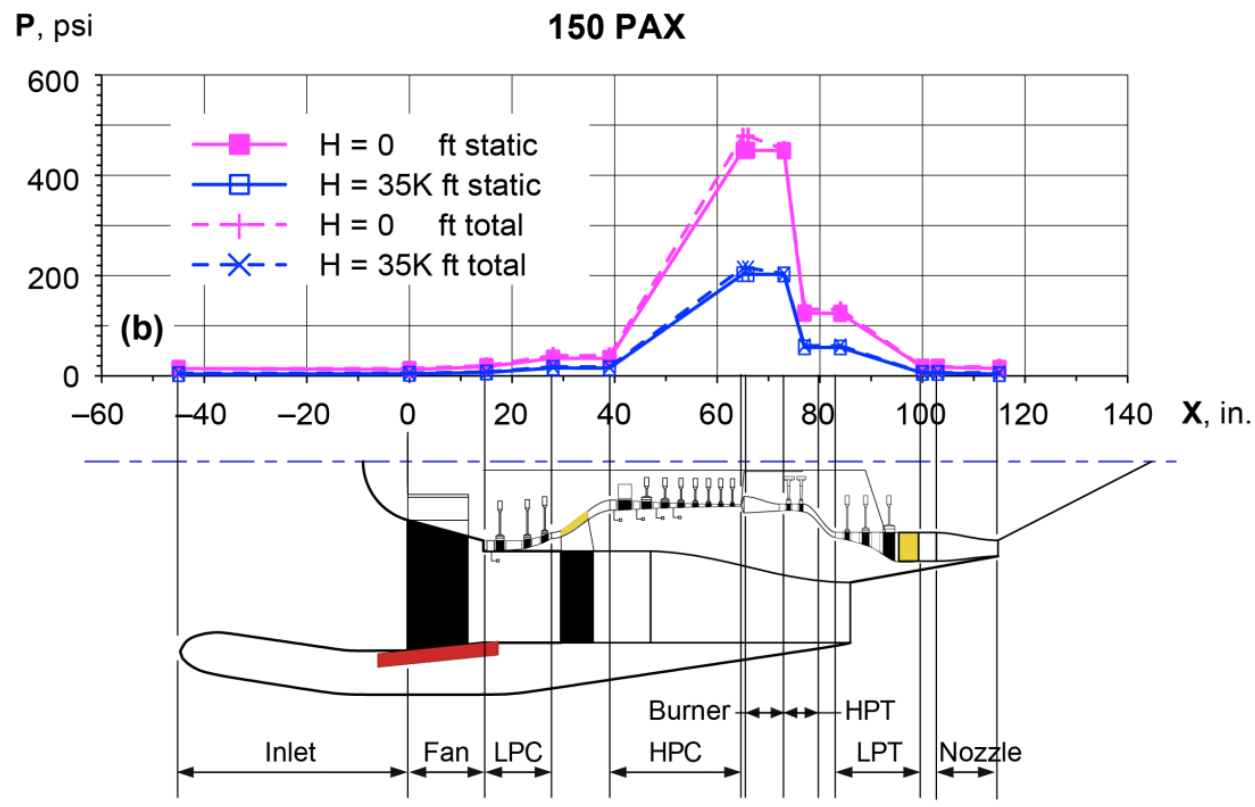

Figure 5b.-150 PAX engine-static and total pressures. 


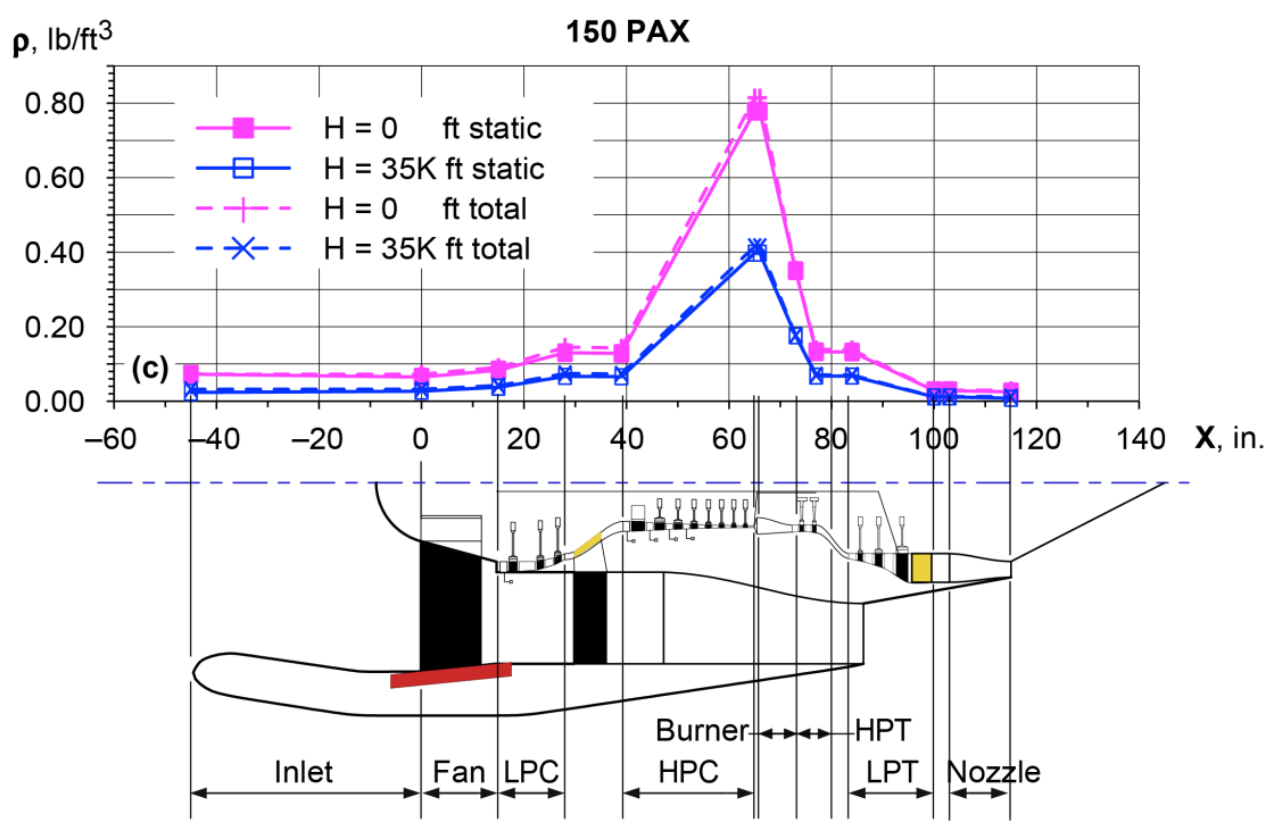

Figure 5c.-150 PAX engine-static and total densities.

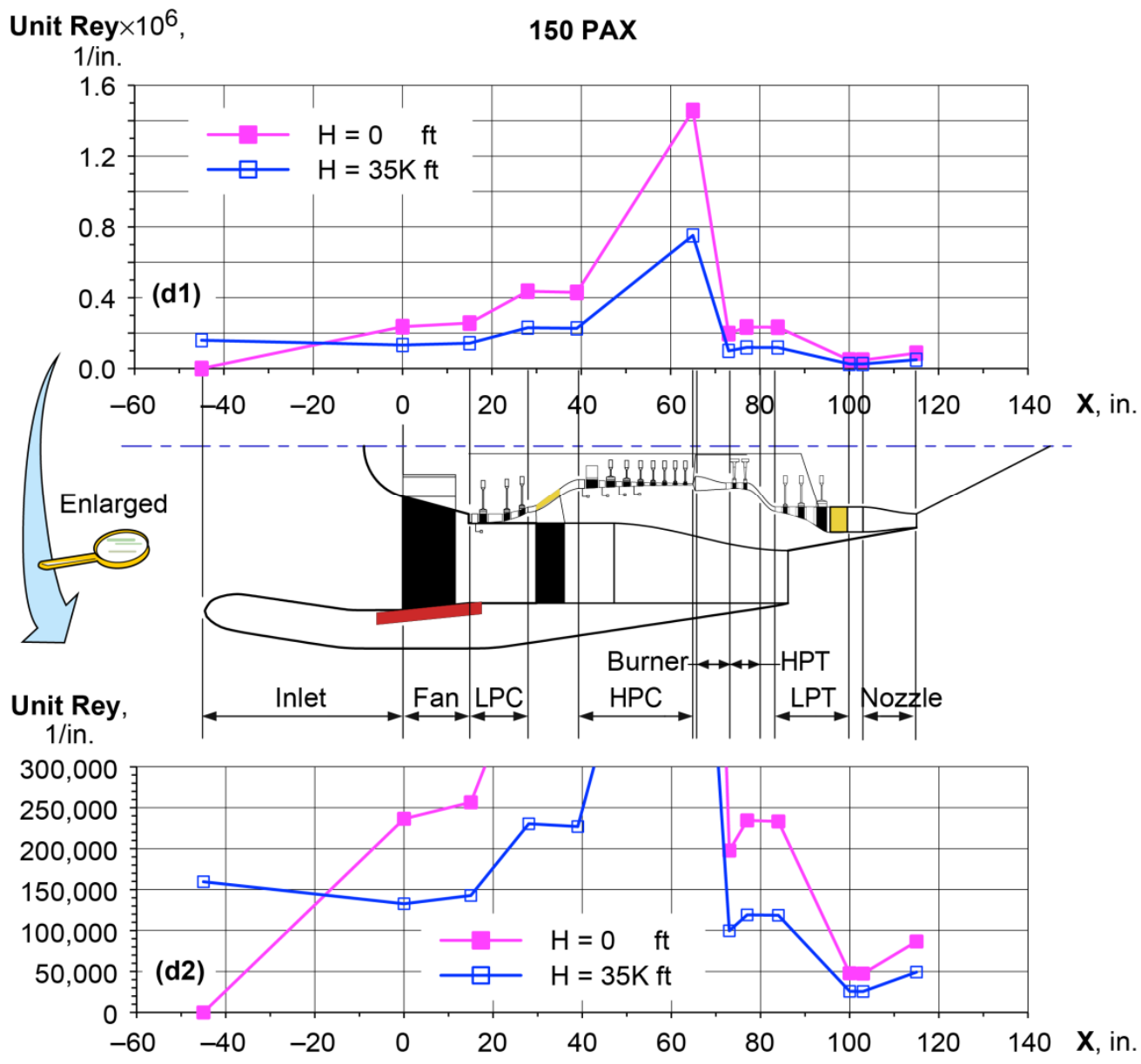

Figure 5d.-150 PAX engine-unit Reynolds numbers. (d1) Full unit Reynolds number scale. (d2) Enlargement. 


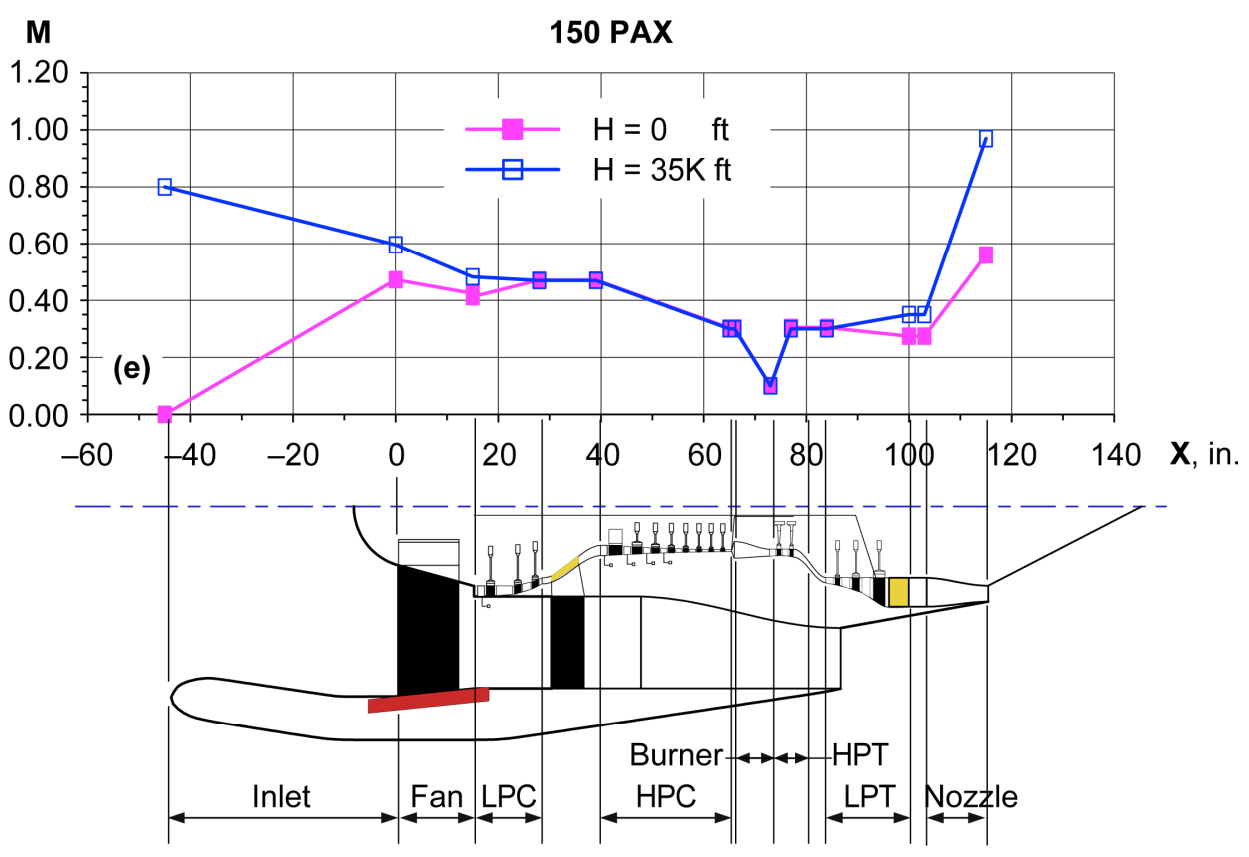

Figure 5e. 150 PAX engine-Mach number.

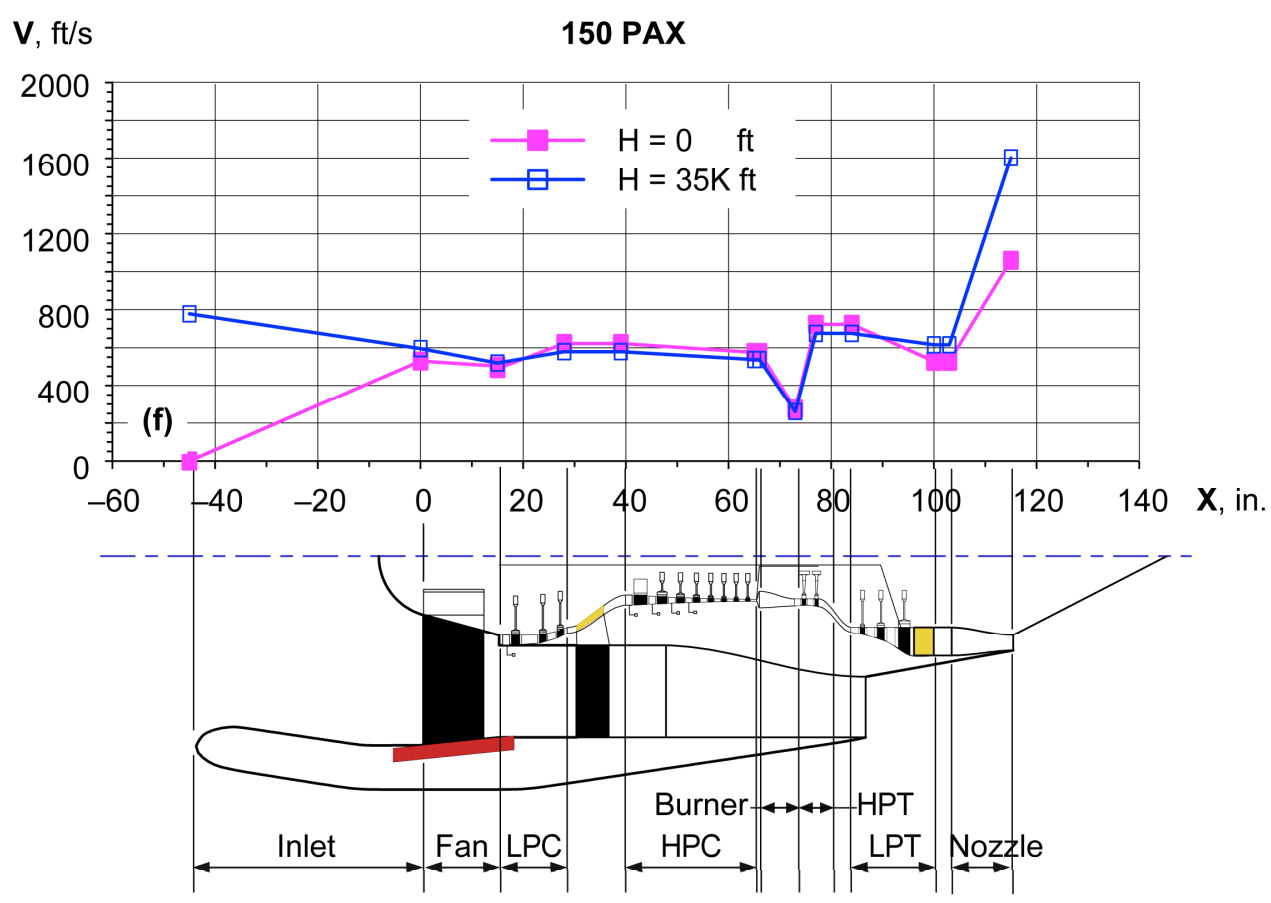

Figure 5f. 150 PAX engine-Velocity.

Figure 5.-Engine data for 150 PAX engine model (a) Temperatures. (b) Pressures.

(c) Densities. (d) Unit Reynolds number. (e) Mach number. (f) Velocity, for sea-level takeoff and 35,000 ft cruise. 


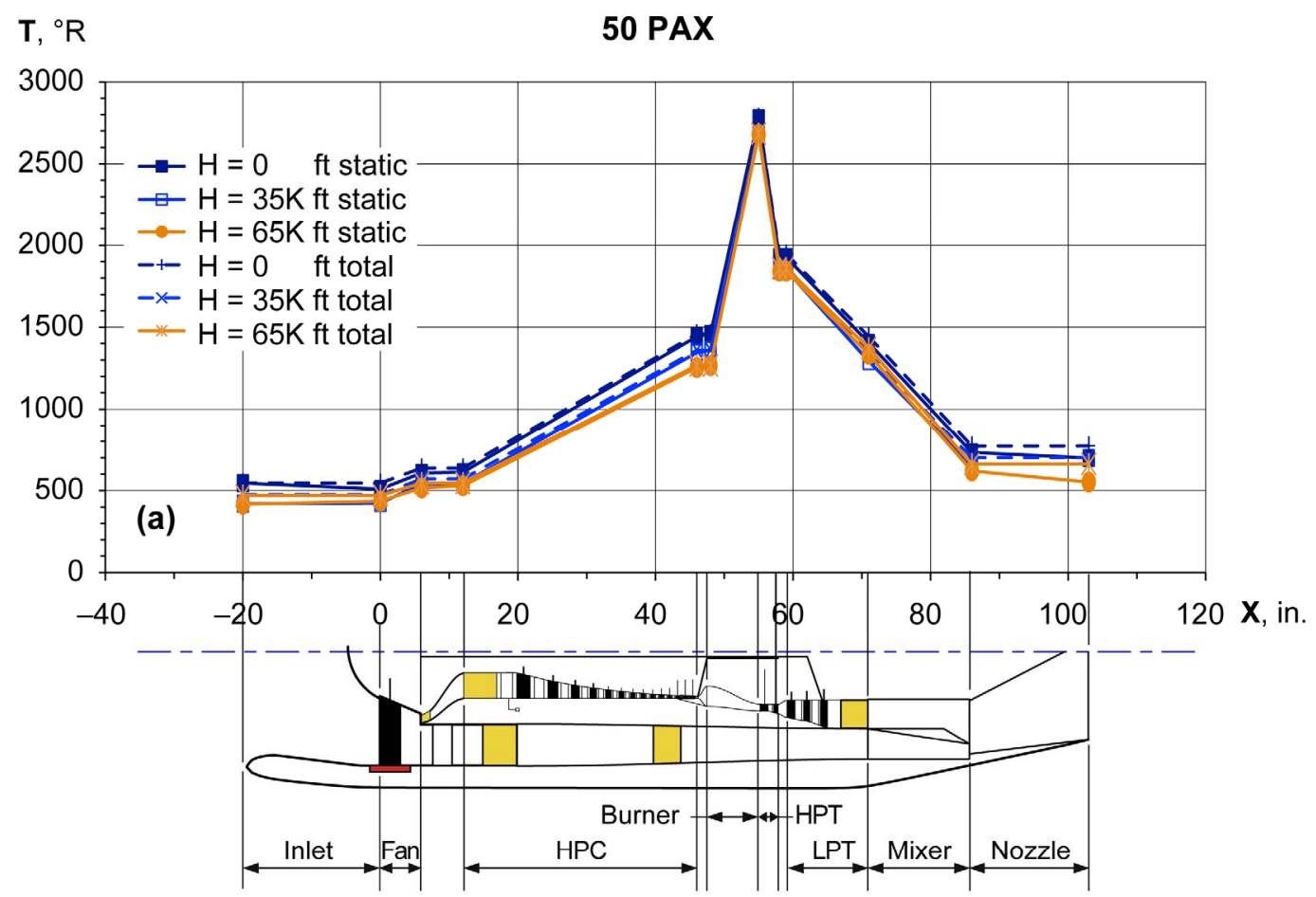

Figure 6a.-50 PAX engine-static and total temperatures, $M=0$ at sea level, $M=0.8$ at $35,000 \mathrm{ft}$ and $65,000 \mathrm{ft}$.

$\mathbf{P}, \mathrm{psi}$

50 PAX

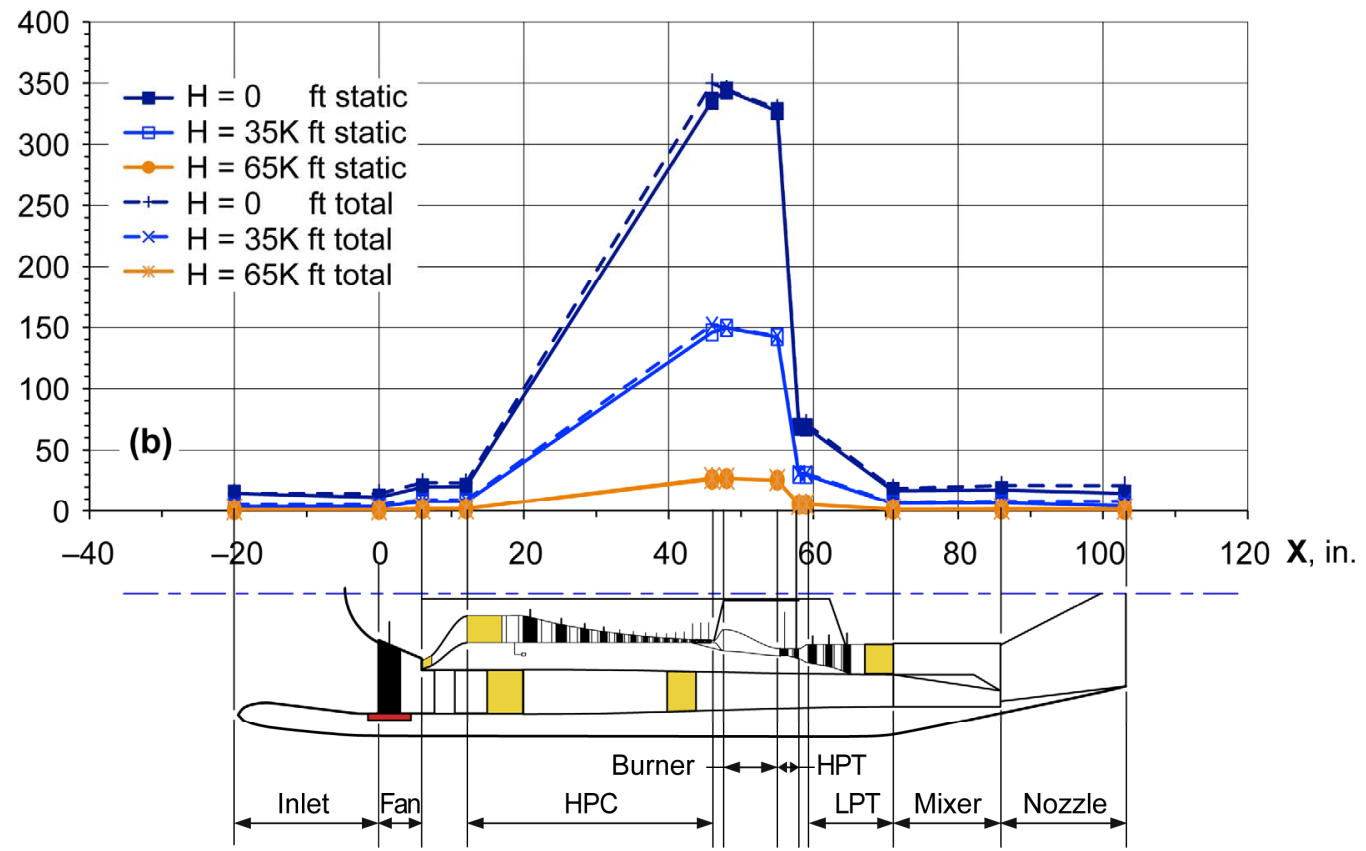

Figure $6 \mathrm{~b} .-50$ PAX engine-static and total pressures, $M=0$ at sea level, $M=0.8$ at $35,000 \mathrm{ft}$ and $65,000 \mathrm{ft}$. 
$\rho, \mathrm{lb} / \mathrm{tt}^{3}$

50 PAX

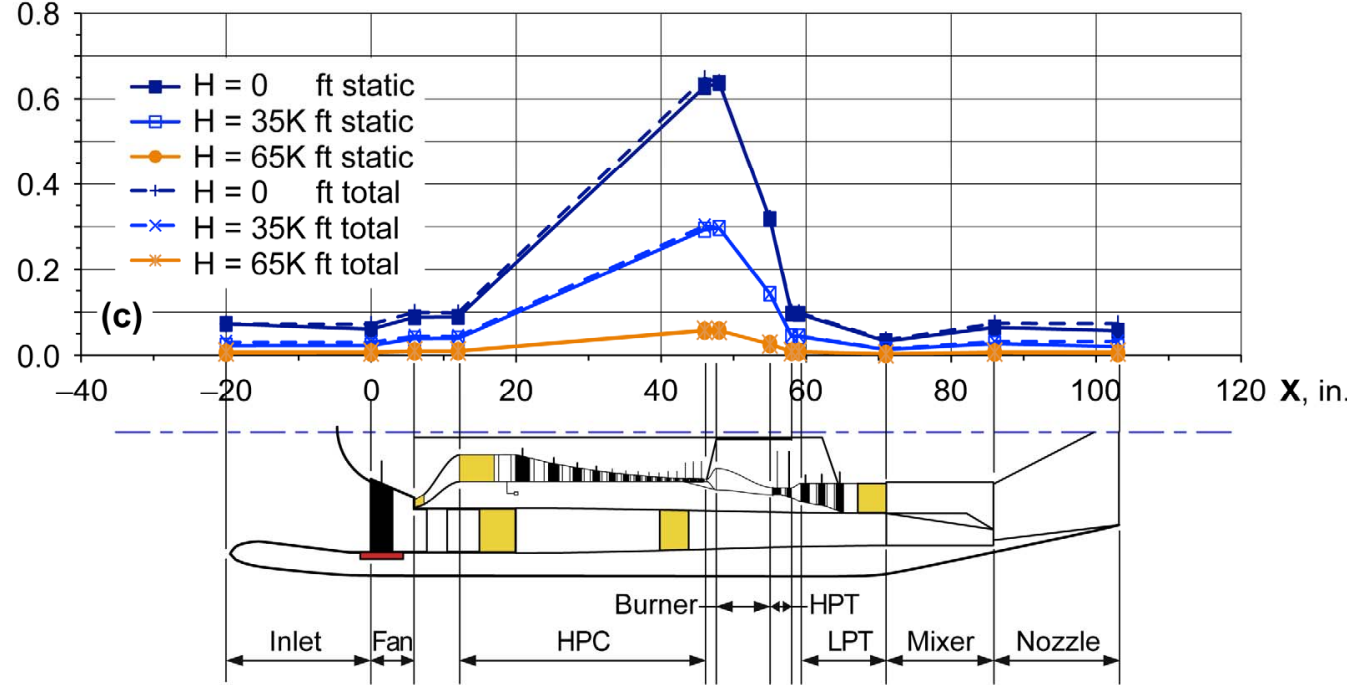

Figure 6c.-50 PAX engine-static and total densities, $M=0$ at sea level, $M=0.8$ at $35,000 \mathrm{ft}$ and $65,000 \mathrm{ft}$.

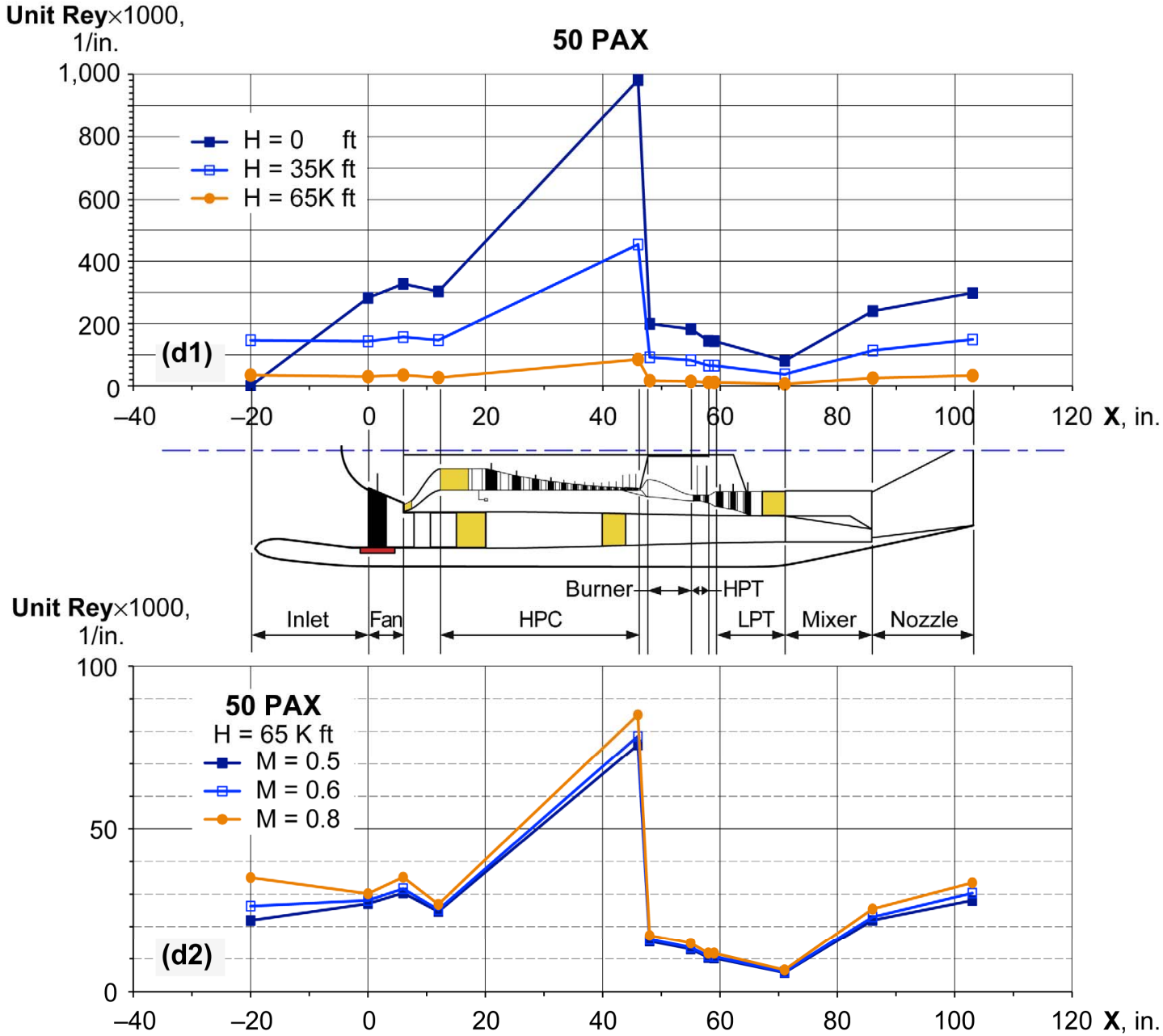

Figure 6d.-50 PAX engine-unit Reynolds number. (d1) For $\mathrm{M}=0$ at sea level, $\mathrm{M}=0.8$ at $35,000 \mathrm{ft}$ and $65,000 \mathrm{ft}$. (d2) For $\mathrm{M}=0.5,0.6$, and 0.8 at $65,000 \mathrm{ft}$. 


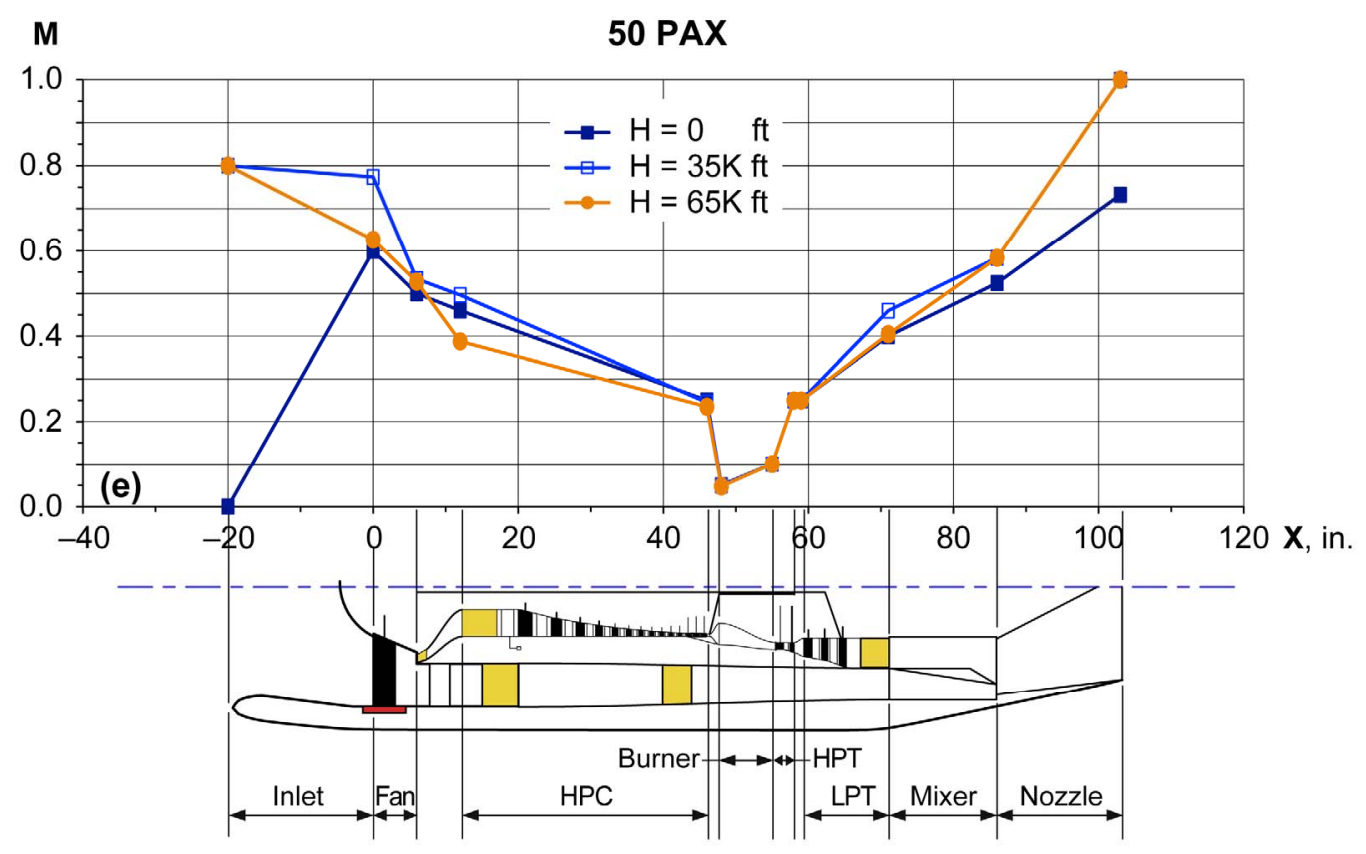

Figure 6e.-50 PAX engine-Mach number, $M=0$ at sea level, $M=0.8$ at $35,000 \mathrm{ft}$ and $65,000 \mathrm{ft}$.

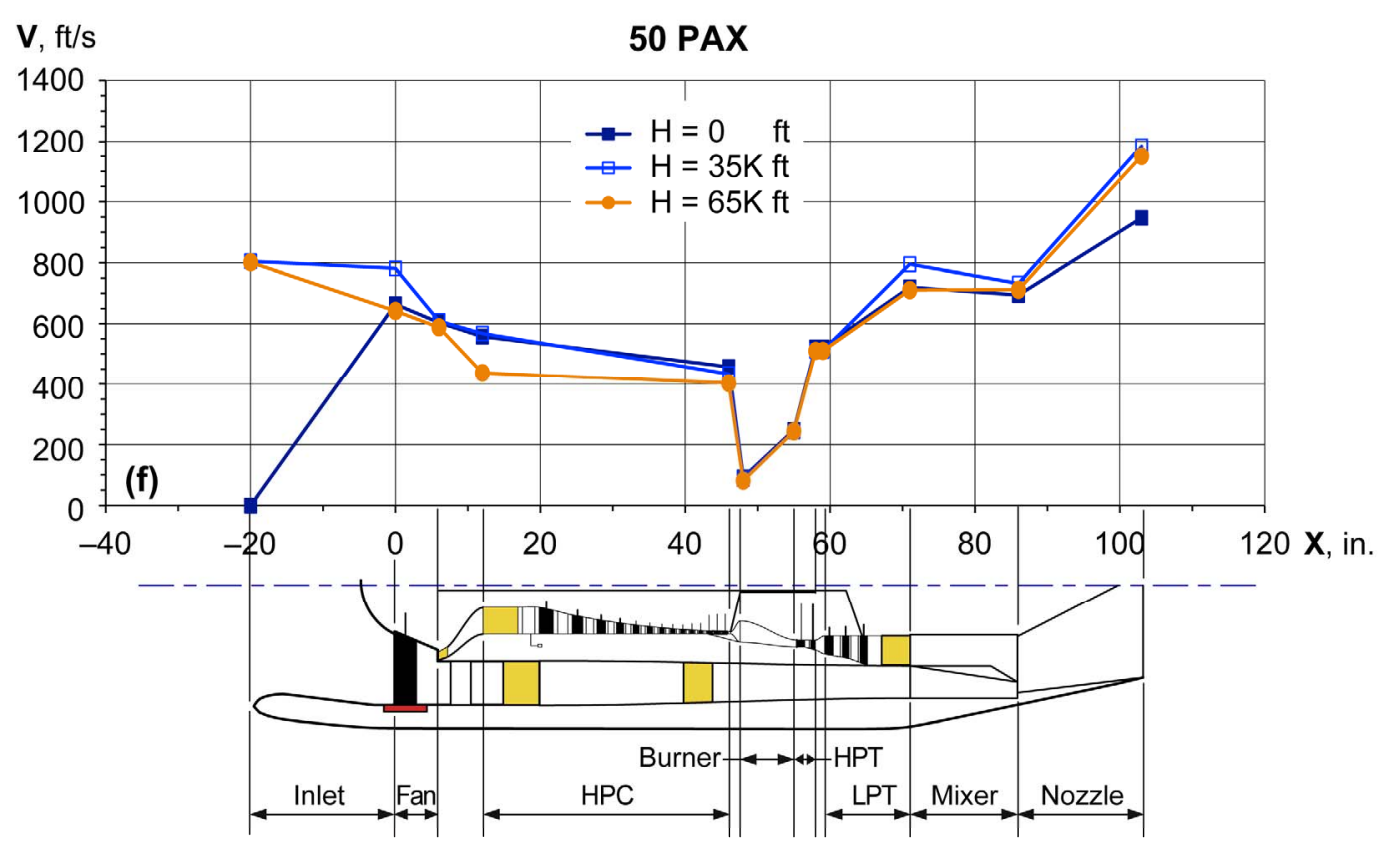

Figure $6 \mathrm{f} .-50 \mathrm{PAX}$ engine-Velocity, $\mathrm{M}=0$ at sea level, $\mathrm{M}=0.8$ at $35,000 \mathrm{ft}$ and $65,000 \mathrm{ft}$.

Figure 6.-Engine data for 50 PAX engine model (a) Temperatures. (b) Pressures. (c) Densities. (d) Unit Reynolds number. (e) Mach number. (f) Velocity, for sea-level takeoff and 35,000 ft and $65,000 \mathrm{ft}$ cruise. 


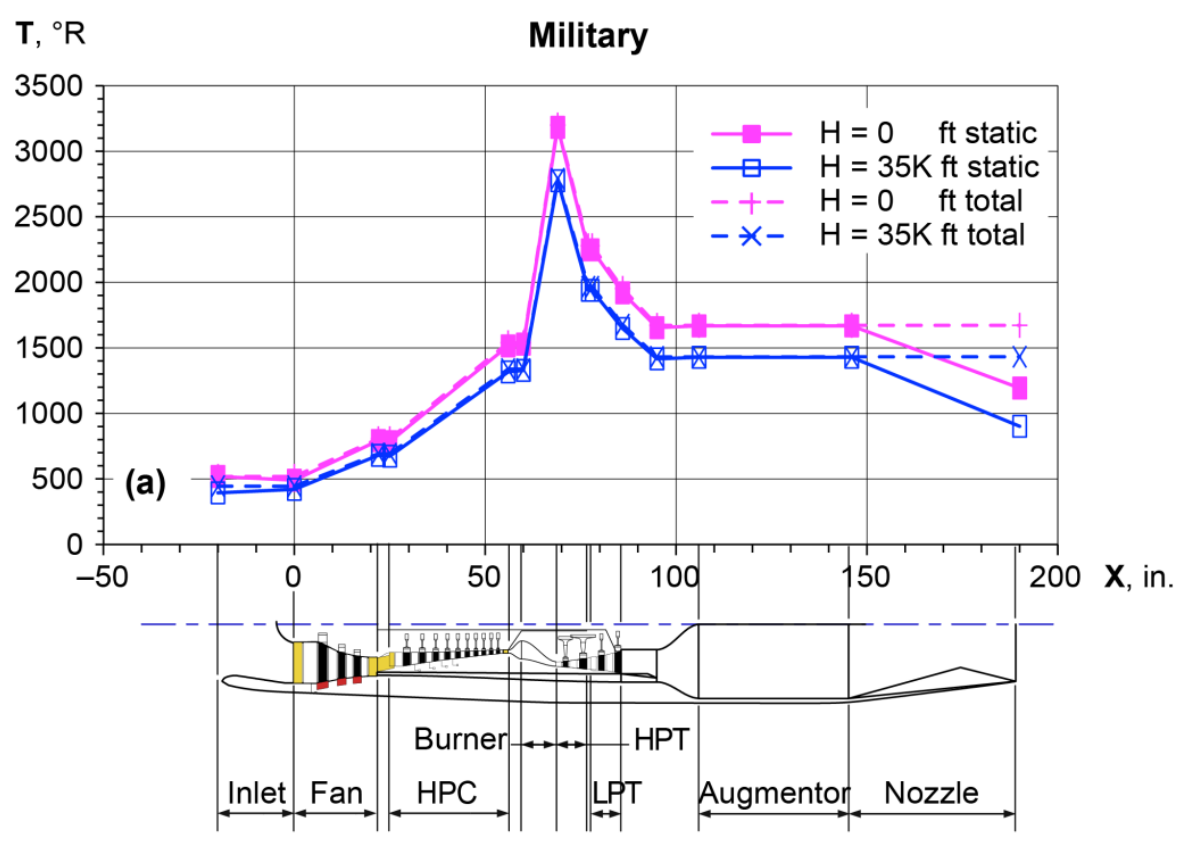

Figure 7a.-Military jet fighter engine-static and total temperatures.

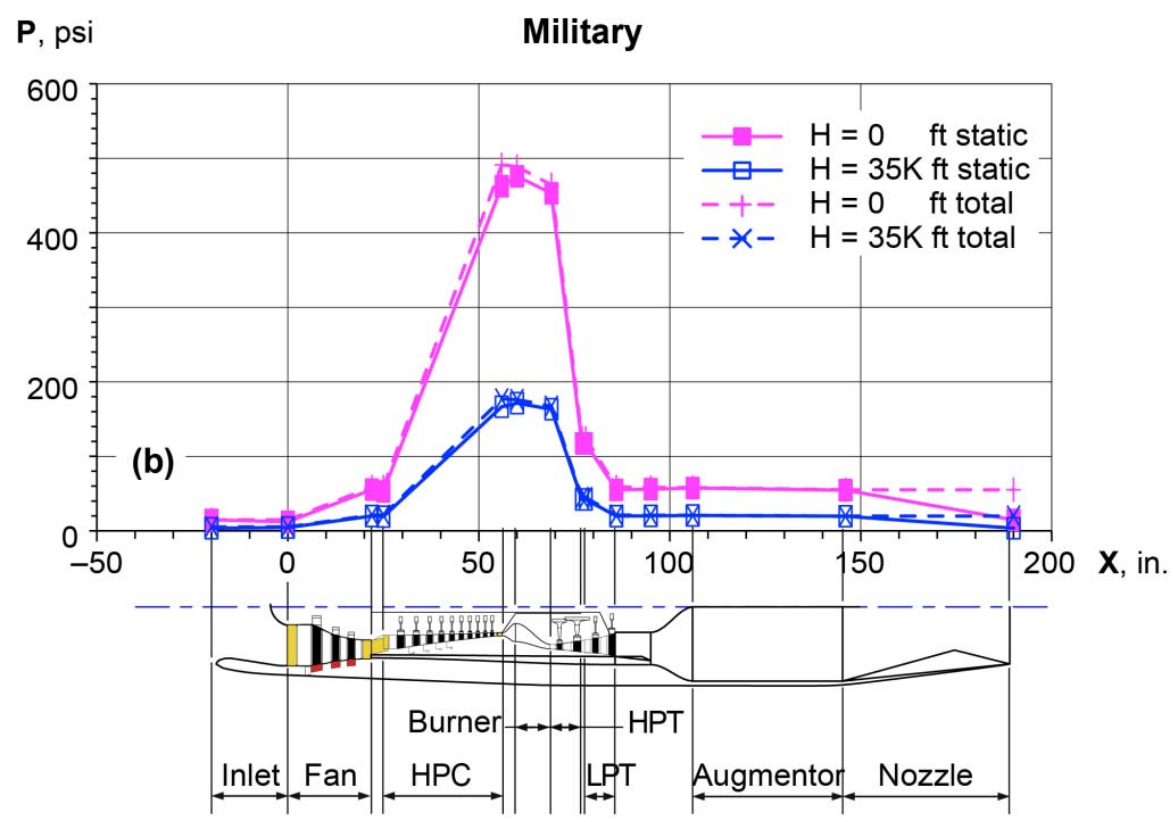

Figure $7 \mathrm{~b}$.-Military jet fighter engine-static and total pressures. 


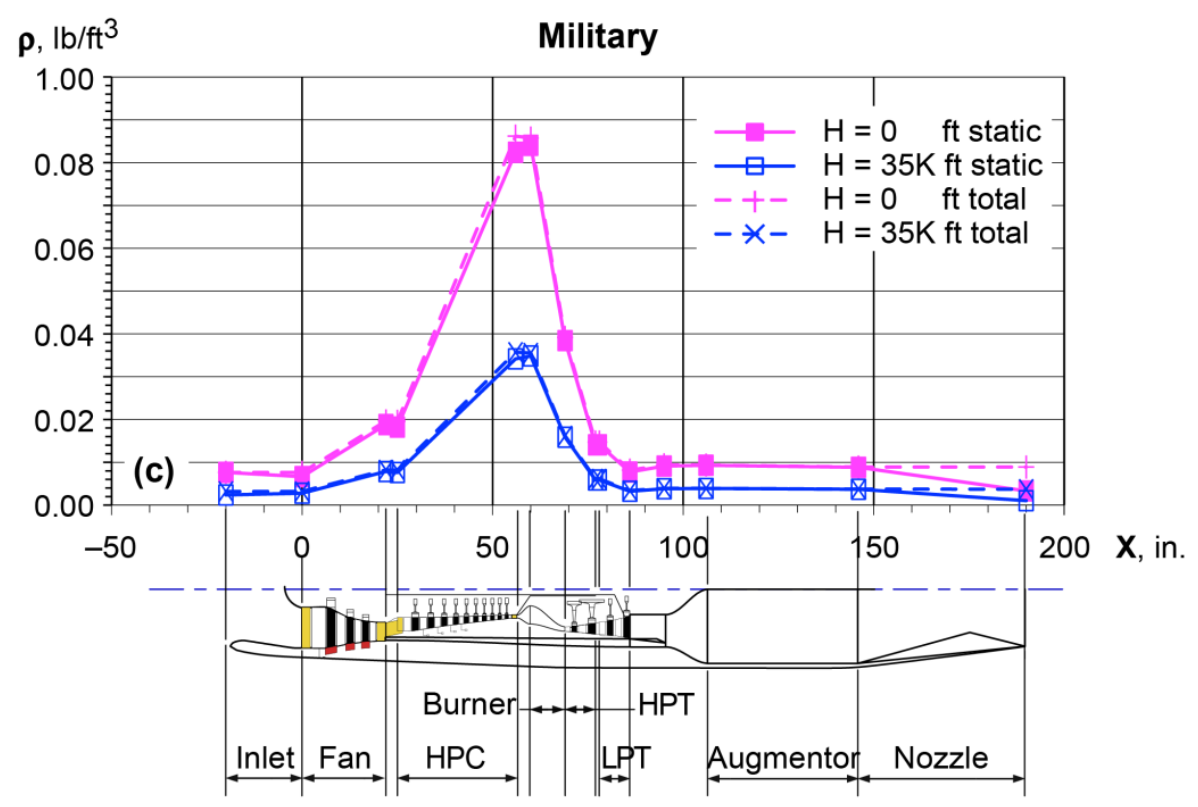

Figure 7c.-Military jet fighter engine-static and total densities.

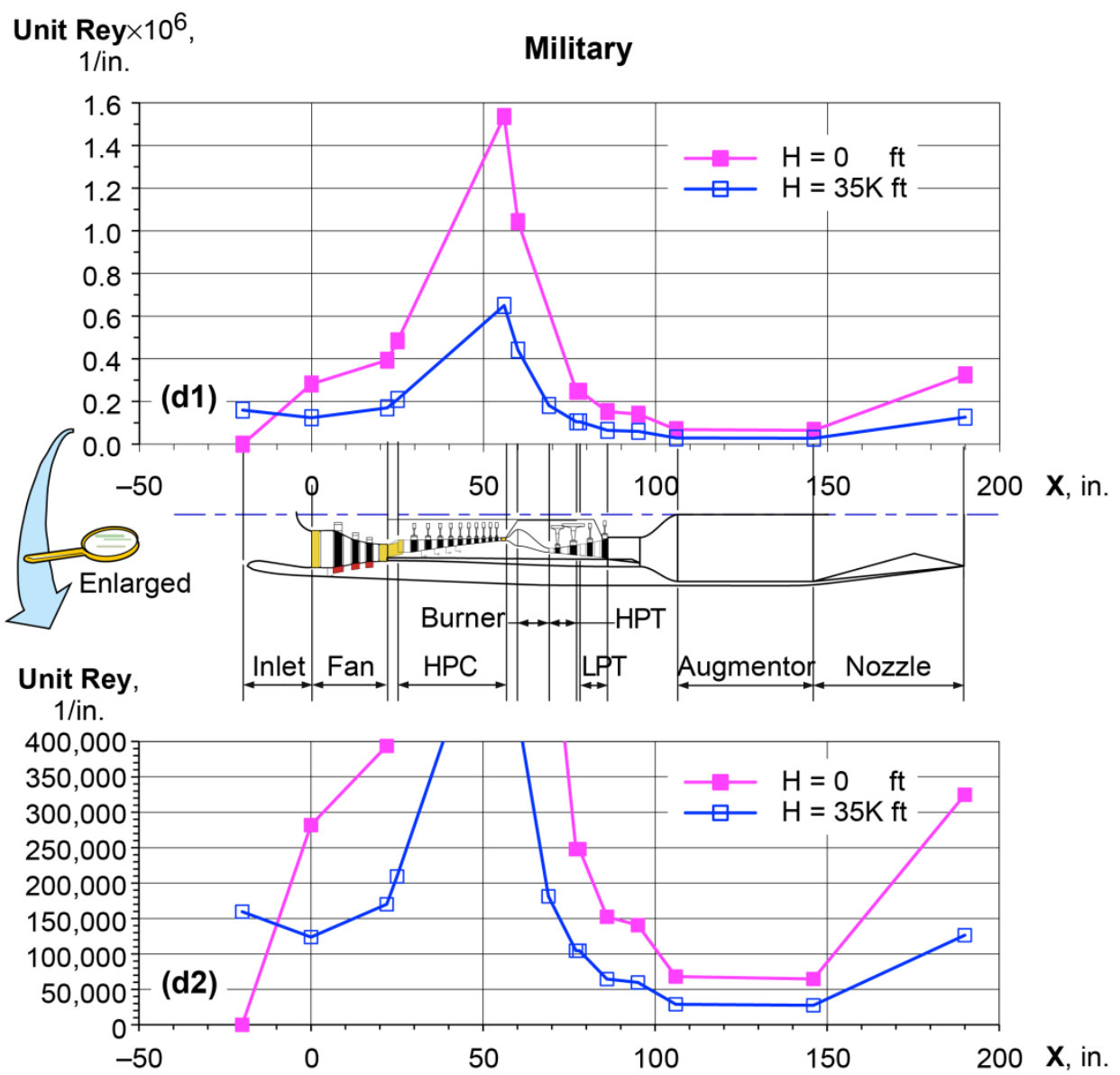

Figure 7d.-Military jet fighter engine-unit Reynolds number. (d1) Full unit Reynolds number scale. (d2) Enlargement. 


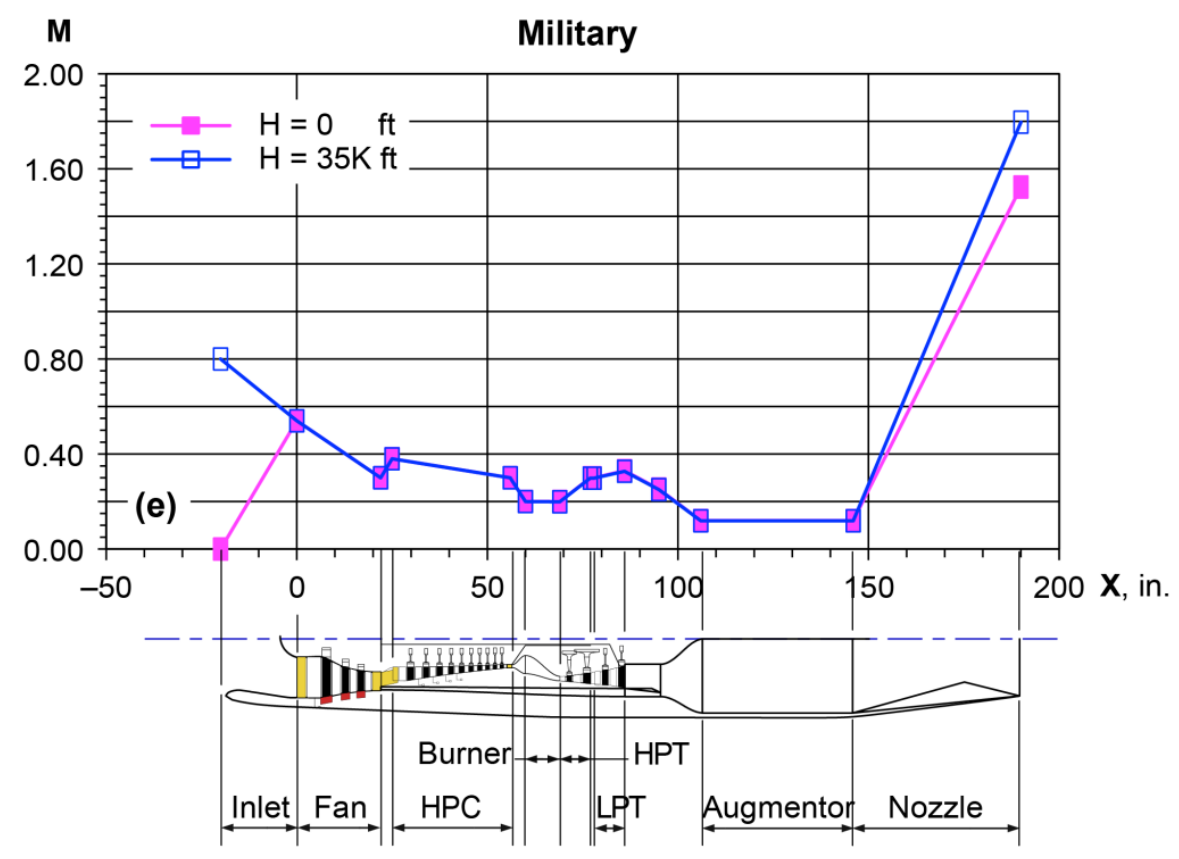

Figure 7e.-Military jet fighter engine-Mach number.

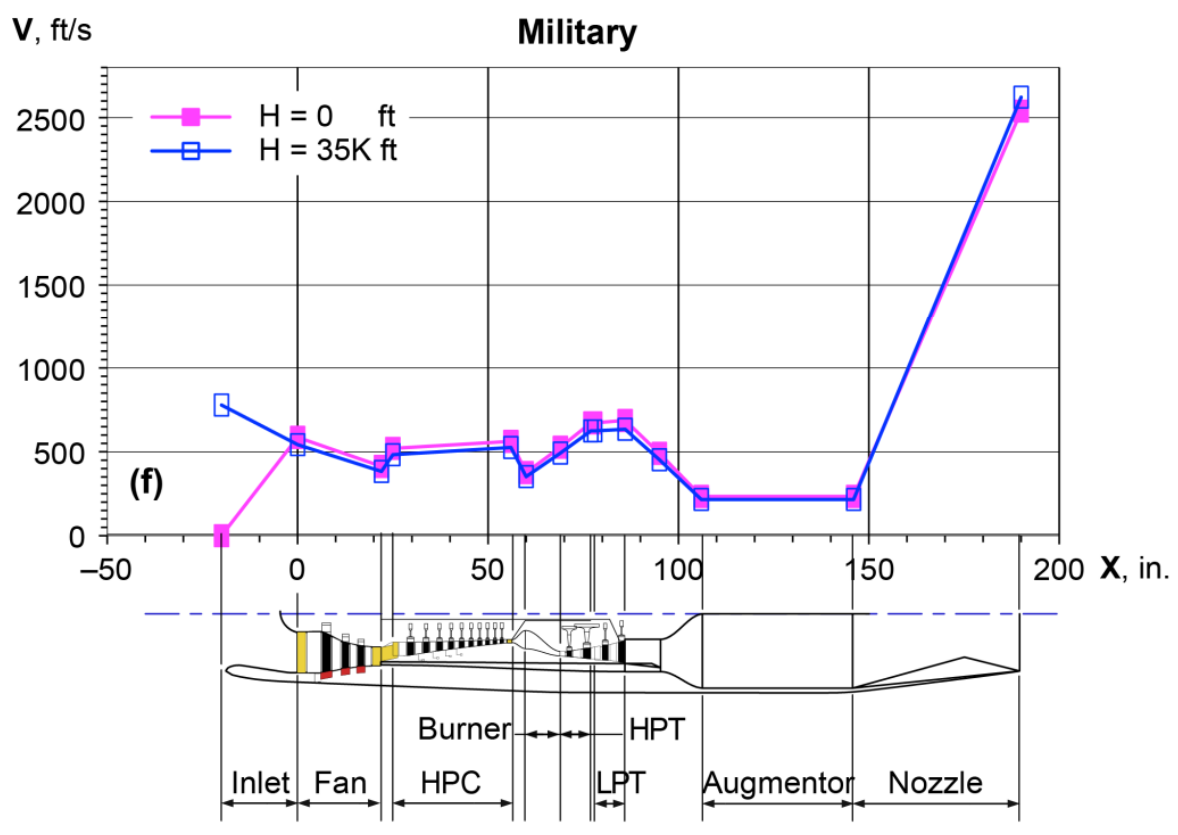

Figure 7f.-Military jet fighter engine-Velocity.

Figure 7.-Military jet fighter engine model (a) Temperatures. (b) Pressures. (c) Densities. (d) Unit Reynolds number. (e) Mach number. (f) Velocity, for sea-level takeoff and 35,000 ft cruise. 


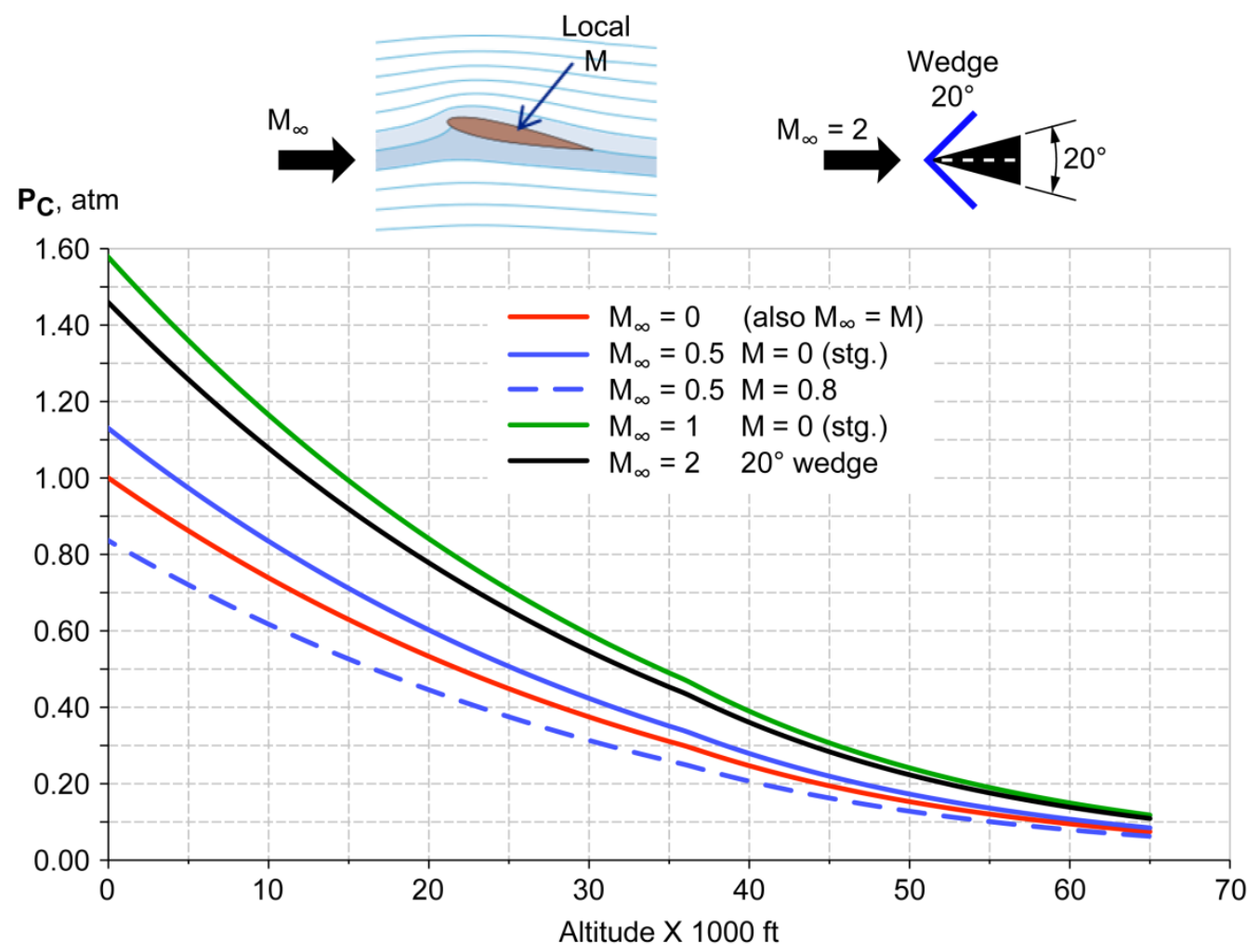

Figure 8.-Test-chamber pressure for application in air vehicle in altitude flight. The figure shows the chamber pressure needed to match density on the body for (1) Stationary vehicle $M_{\infty}=0$ and a flat-plate at zero angle of attack $M=M_{\infty}$, (2) Flight Mach number $M_{\infty}=0.5$ and local Mach numbers $M=0$ (stagnation point) and $M=0.8$, (3) Flight Mach numbers $M_{\infty}=1$ and local Mach number $M=0$ (stagnation point), without shocks, and, (4) a $20^{\circ}$ wedge with shock wave flying at $\mathrm{M}_{\infty}=2$. 

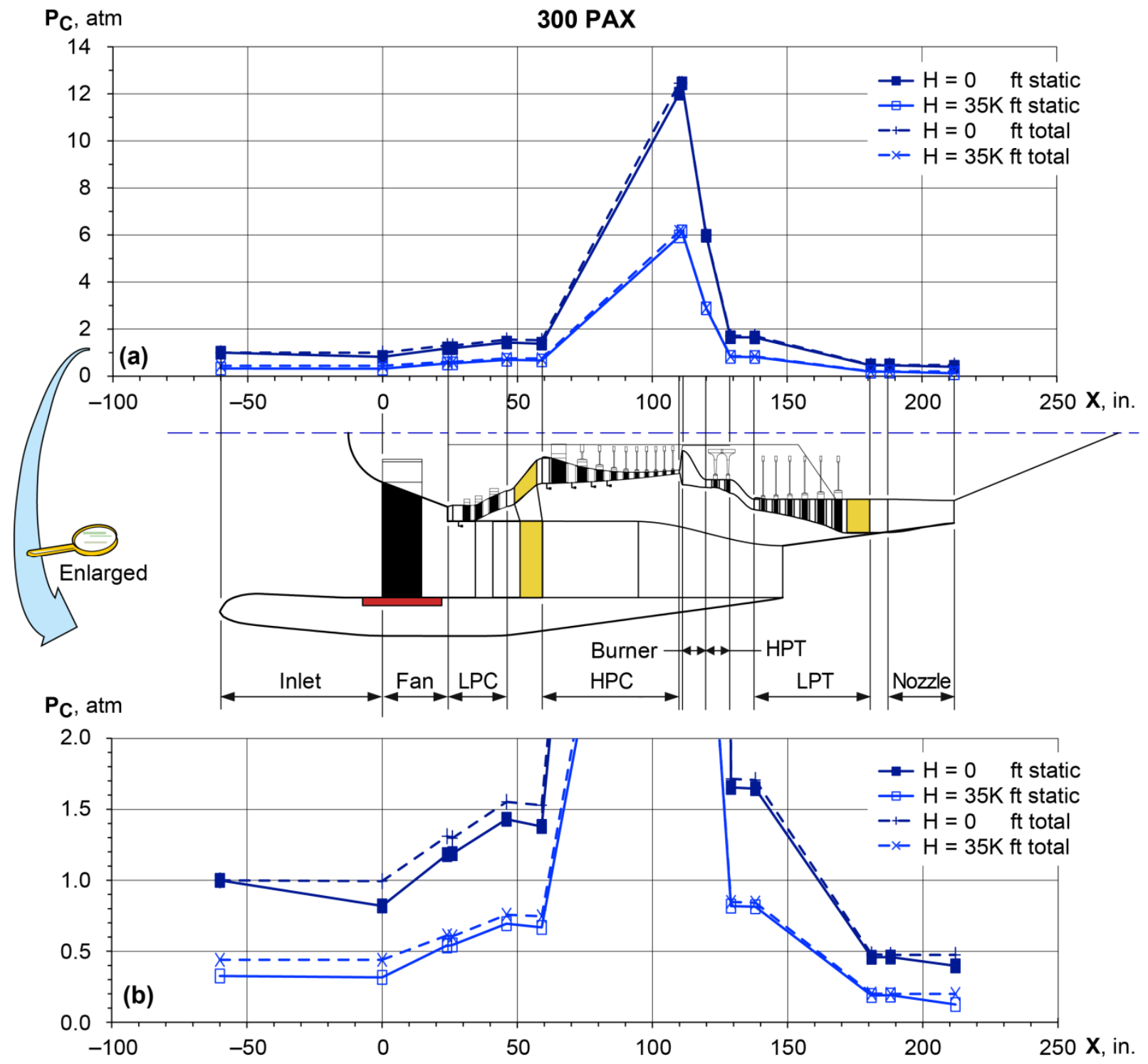

Figure 9a.-300 PAX engine-chamber pressure. (a) Full scale plot. (b) Enlargement of (a). 

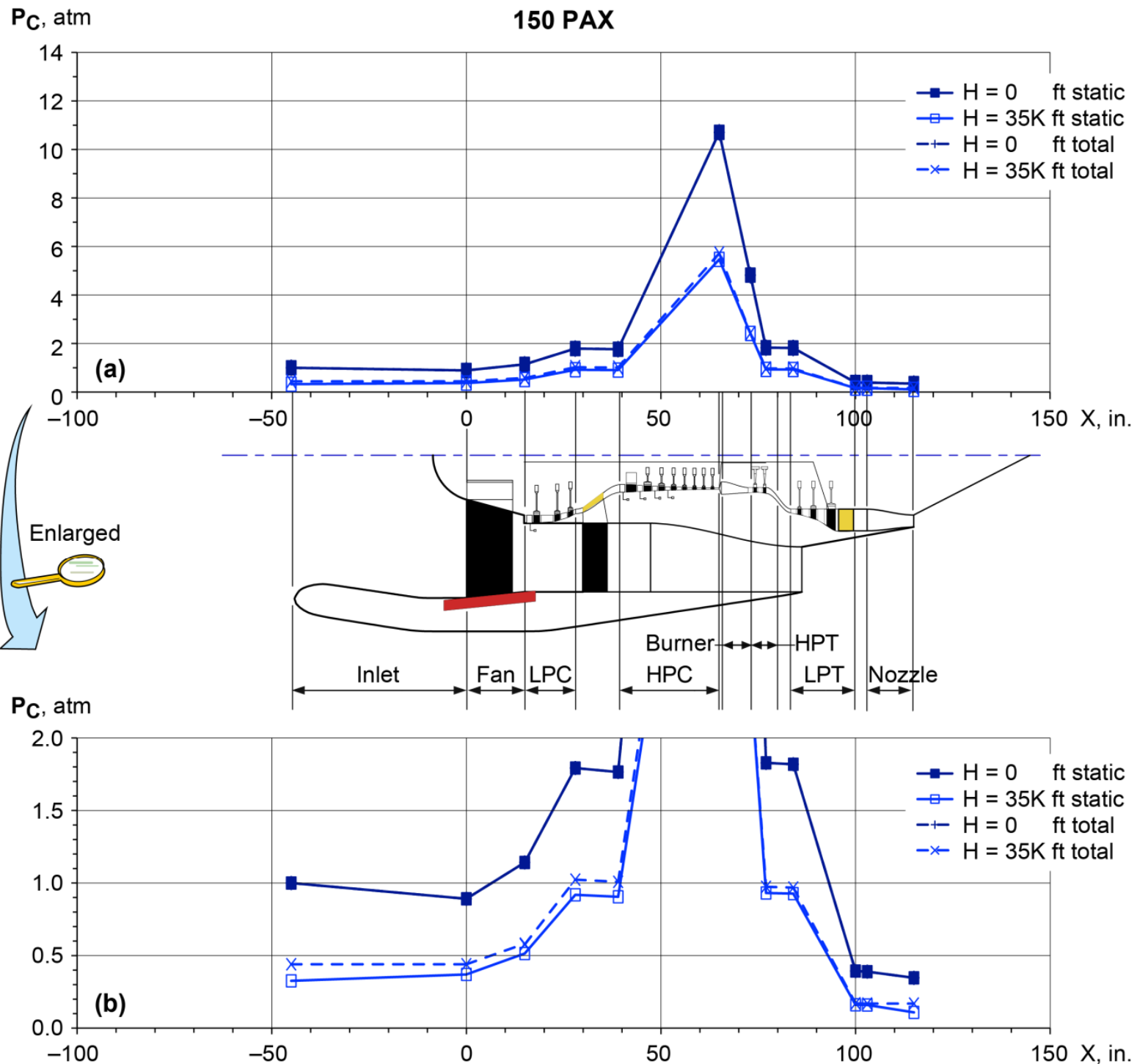

Figure 9b.-150 PAX engine-chamber pressure. (a) Full scale plot. (b) Enlargement of (a). 

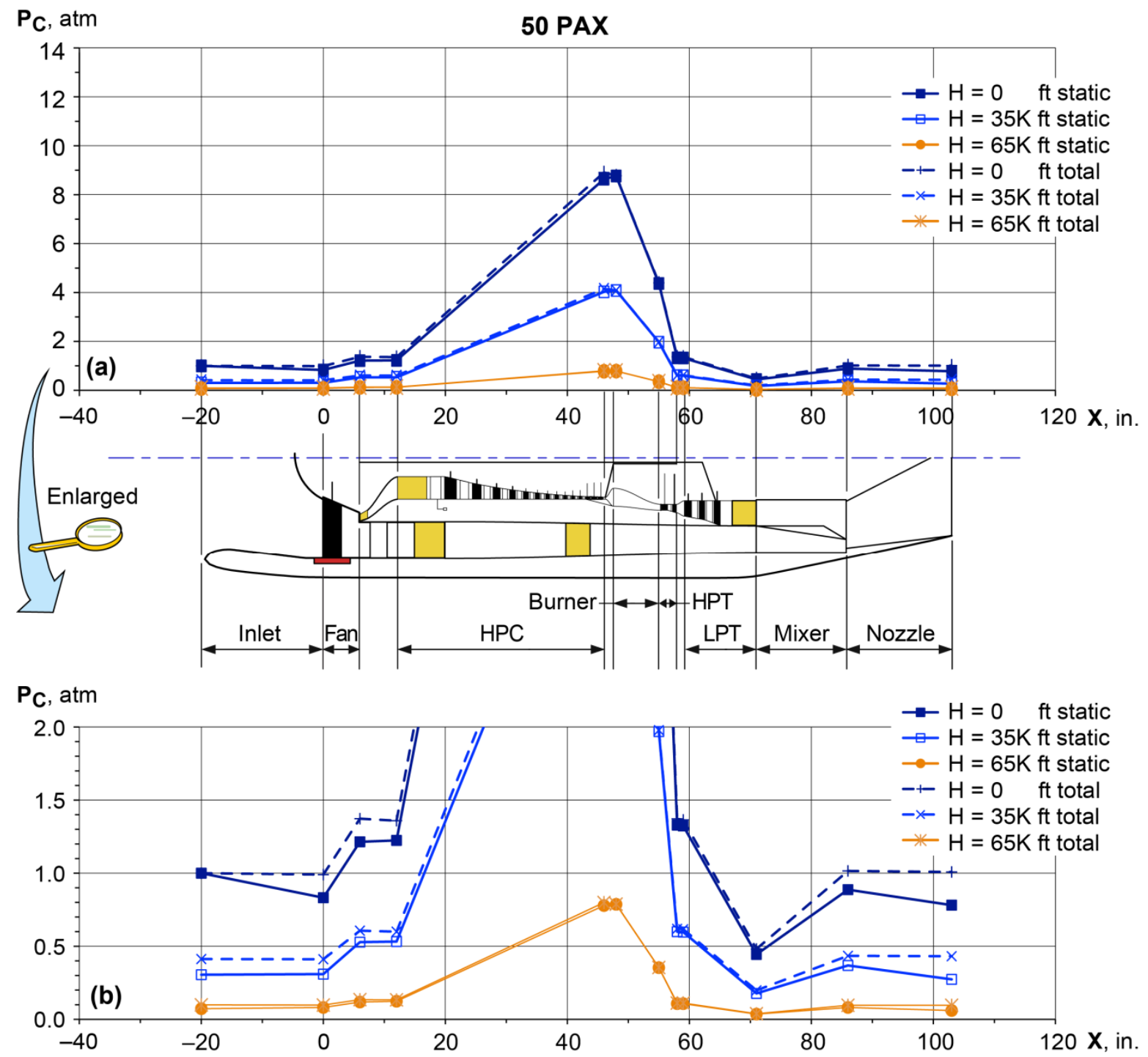

Figure 9c.-50 PAX engine-chamber pressure. (a) Full scale plot. (b) Enlargement of (a). 


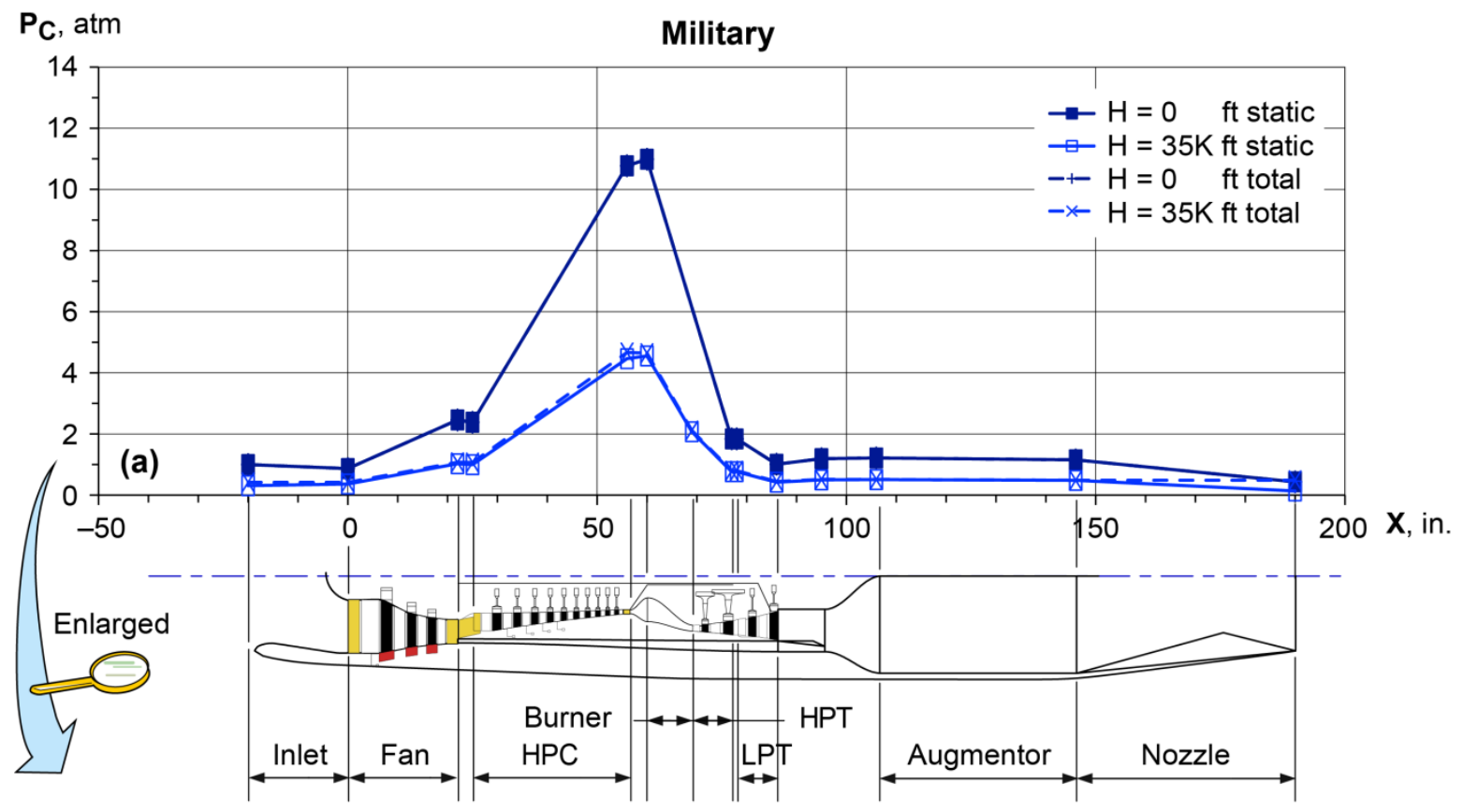

$\mathrm{PC}_{\mathrm{C}}$ atm

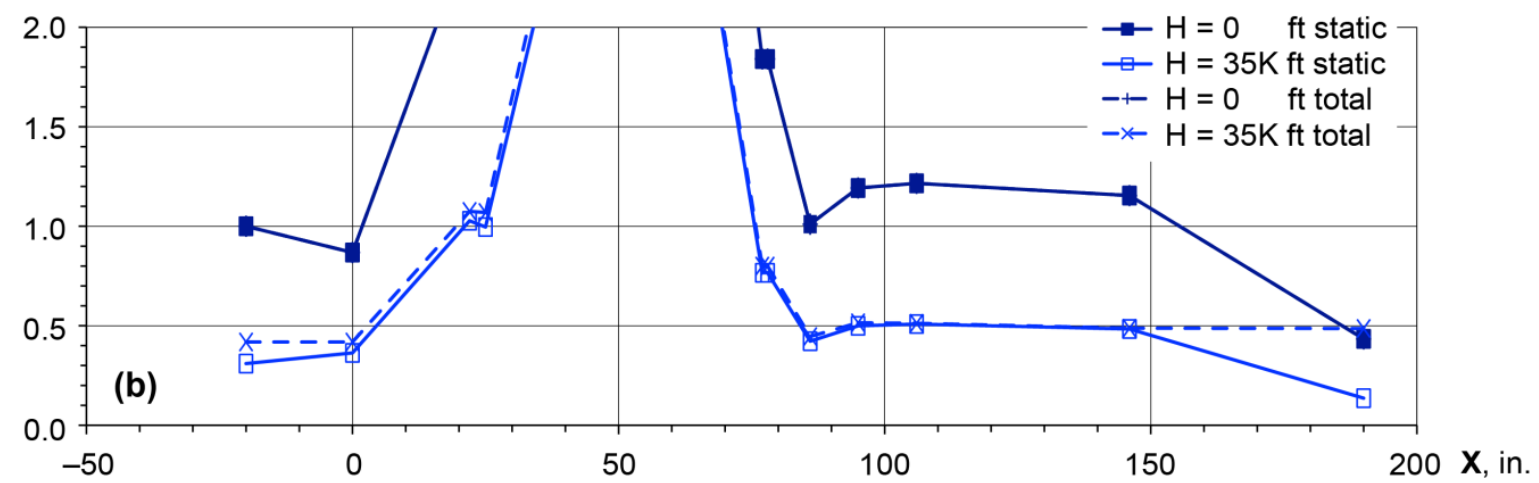

Figure 9d.-Military engine-chamber pressure. (a) Full scale plot. (b) Enlargement of (a). 


\begin{tabular}{|c|c|c|}
\hline \multicolumn{2}{|c|}{ REPORT DOCUMENTATION PAGE } & $\begin{array}{l}\text { Form Approved } \\
\text { OMB No. 0704-0188 }\end{array}$ \\
\hline \multicolumn{3}{|c|}{$\begin{array}{l}\text { The public reporting burden for this collection of information is estimated to average } 1 \text { hour per response, including the time for reviewing instructions, searching existing data sources, gathering and maintaining the } \\
\text { data needed, and completing and reviewing the collection of information. Send comments regarding this burden estimate or any other aspect of this collection of information, including suggestions for reducing this } \\
\text { burden, to Department of Defense, Washington Headquarters Services, Directorate for Information Operations and Reports (0704-0188), } 1215 \text { Jefferson Davis Highway, Suite } 1204 \text {, Arlington, VA } 22222-4302 \text {. } \\
\text { Respondents should be aware that notwithstanding any other provision of law, no person shall be subject to any penalty for failing to comply with a collection of information if it does not display a currently valid OMB } \\
\text { control number. } \\
\text { PLEASE DO NOT RETURN YOUR FORM TO THE ABOVE ADDRESS. }\end{array}$} \\
\hline $\begin{array}{l}\text { 1. REPORT DATE (DD-MM-YYYY) } \\
01-07-2011\end{array}$ & $\begin{array}{l}\text { 2. REPORT TYPE } \\
\text { Technical Memorandum }\end{array}$ & 3. DATES COVERED (From - To) \\
\hline \multirow{3}{*}{\multicolumn{2}{|c|}{$\begin{array}{l}\text { 4. TITLE AND SUBTITLE } \\
\text { DBD Plasma Actuators for Flow Control in Air Vehicles and Jet Engines--Simulation of } \\
\text { Flight Conditions in Test Chambers by Density Matching }\end{array}$}} & 5a. CONTRACT NUMBER \\
\hline & & 5b. GRANT NUMBER \\
\hline & & 5c. PROGRAM ELEMENT NUMBER \\
\hline \multirow{3}{*}{\multicolumn{2}{|c|}{$\begin{array}{l}\text { 6. AUTHOR(S) } \\
\text { Ashpis, David, E.; Thurman, Douglas, R. }\end{array}$}} & 5d. PROJECT NUMBER \\
\hline & & 5e. TASK NUMBER \\
\hline & & $\begin{array}{l}\text { 5f. WORK UNIT NUMBER } \\
\text { WBS 561581.02.08.03.21.13.02 }\end{array}$ \\
\hline \multicolumn{2}{|c|}{$\begin{array}{l}\text { 7. PERFORMING ORGANIZATION NAME(S) AND ADDRESS(ES) } \\
\text { National Aeronautics and Space Administration } \\
\text { John H. Glenn Research Center at Lewis Field } \\
\text { Cleveland, Ohio 44135-3191 }\end{array}$} & $\begin{array}{l}\text { 8. PERFORMING ORGANIZATION } \\
\text { REPORT NUMBER } \\
\text { E-17602-1 }\end{array}$ \\
\hline \multirow{2}{*}{\multicolumn{2}{|c|}{$\begin{array}{l}\text { 9. SPONSORING/MONITORING AGENCY NAME(S) AND ADDRESS(ES) } \\
\text { National Aeronautics and Space Administration } \\
\text { Washington, DC 20546-0001 } \\
\text { and } \\
\text { U.S. Army Research Laboratory } \\
\text { Adelphi, Maryland 20783-1145 }\end{array}$}} & $\begin{array}{l}\text { 10. SPONSORING/MONITOR'S } \\
\text { ACRONYM(S) } \\
\text { NASA, ARL }\end{array}$ \\
\hline & & $\begin{array}{l}\text { 11. SPONSORING/MONITORING } \\
\text { REPORT NUMBER } \\
\text { NASA/TM-2011-217006-REV1 }\end{array}$ \\
\hline
\end{tabular}

\section{DISTRIBUTION/AVAILABILITY STATEMENT}

Unclassified-Unlimited

Subject Categories: 02, 05, 07, 13, and 75

Available electronically at http://www.sti.nasa.gov

This publication is available from the NASA Center for AeroSpace Information, 443-757-5802

\section{SUPPLEMENTARY NOTES}

This printing replaces NASA/TM--2011-217006, March 2011.

\section{ABSTRACT}

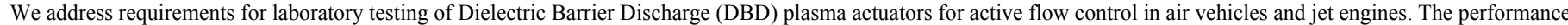
of these actuators depends on the gas discharge properties, which in turn, depend on the pressure and temperature. When performing a characterization of actuators in a

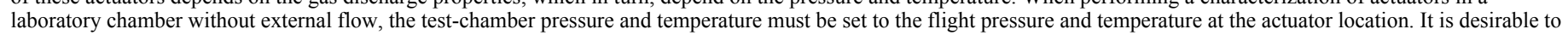

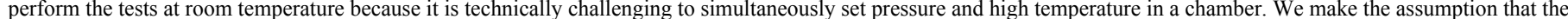

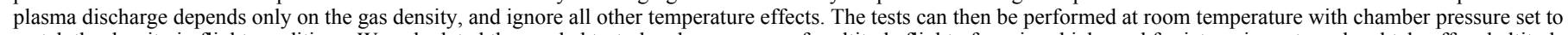

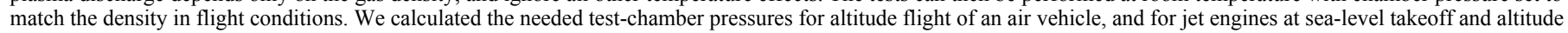

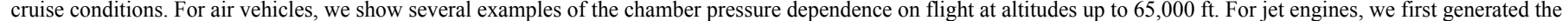

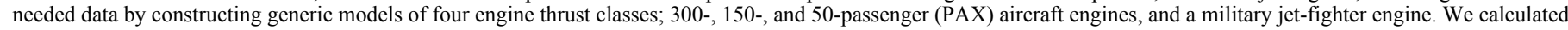
the static and total pressure, temperature, and density distributions along the engine for sea-level takeoff and for altitude cruise conditions, and we present the corresponding test-chamber pressures. The range is from 12.4 to $0.03 \mathrm{~atm}$, depending on the altitude, the engine class, and the placement of the actuator. For example, if a DBD plasma actuator is placed at the compressor exit of a 300 PAX engine, it must be tested at $12.4 \mathrm{~atm}$ for takeoff, and at 6 atm for cruise. If it is placed at the low-pressure turbine exit,

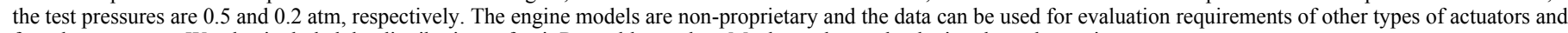
for other purposes. We also included the distributions of unit Reynolds number, Mach number and velocity along the engines.

\section{SUBJECT TERMS}

Jet engines; Aeropropulsion; Turbomachinery; Compressor; Turbine; Gas turbine; Plasma; Dielectric barrier discharge; Flow control

\begin{tabular}{|c|c|c|c|c|}
\hline \multicolumn{3}{|c|}{ 16. SECURITY CLASSIFICATION OF: } & \multirow{2}{*}{$\begin{array}{l}\text { 17. LIMITATION OF } \\
\text { ABSTRACT } \\
\text { UU }\end{array}$} & \multirow{2}{*}{$\begin{array}{l}\text { 18. NUMBER } \\
\text { OF } \\
\text { PAGES } \\
36\end{array}$} \\
\hline $\begin{array}{l}\text { a. REPORT } \\
U\end{array}$ & $\begin{array}{l}\text { b. ABSTRACT } \\
U\end{array}$ & $\begin{array}{l}\text { c. THIS } \\
\text { PAGE } \\
U\end{array}$ & & \\
\hline
\end{tabular}

19a. NAME OF RESPONSIBLE PERSON STI Help Desk (email:help@sti.nasa.gov) 19b. TELEPHONE NUMBER (include area code) $443-757-5802$ 

